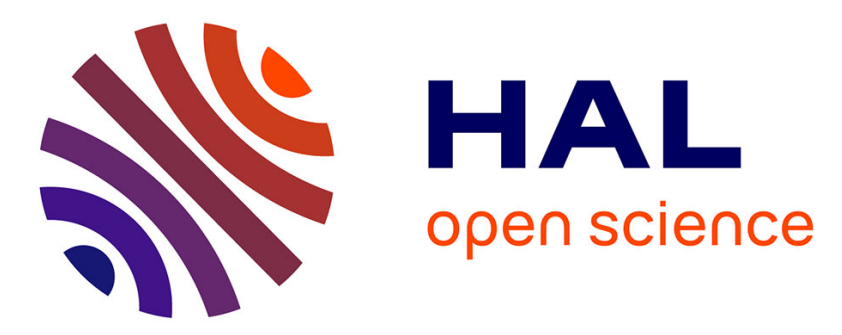

\title{
Nanoscale metamaterials: Meta-MOFs and framework materials with anomalous behavior
}

François-Xavier Coudert, Jack Evans

\section{To cite this version:}

François-Xavier Coudert, Jack Evans. Nanoscale metamaterials: Meta-MOFs and framework materials with anomalous behavior. Coordination Chemistry Reviews, 2019, 388, pp.48-62. 10.1016/j.ccr.2019.02.023 . hal-02168635

\section{HAL Id: hal-02168635 \\ https://hal.science/hal-02168635}

Submitted on 28 Jun 2019

HAL is a multi-disciplinary open access archive for the deposit and dissemination of scientific research documents, whether they are published or not. The documents may come from teaching and research institutions in France or abroad, or from public or private research centers.
L'archive ouverte pluridisciplinaire HAL, est destinée au dépôt et à la diffusion de documents scientifiques de niveau recherche, publiés ou non, émanant des établissements d'enseignement et de recherche français ou étrangers, des laboratoires publics ou privés. 


\title{
Nanoscale Metamaterials: Meta-MOFs and Framework Materials with Anomalous Behavior
}

\author{
François-Xavier Coudert ${ }^{\mathrm{a}}$, Jack D. Evans ${ }^{\mathrm{b}}$ \\ ${ }^{a}$ Chimie ParisTech, PSL University, CNRS, Institut de Recherche de Chimie, Paris, 75005 Paris, \\ France \\ ${ }^{b}$ Anorganische Chemie I, Fachrichtung Chemie und Lebensmittelchemie, Technische Universität \\ Dresden, Bergstrasse 66, 01069 Dresden, Germany
}

\begin{abstract}
As the number of framework materials known and characterized in the literature grows, it becomes apparent that they can carry properties rarely encountered in more conventional, dense inorganic materials. Among these materials with unusual physical or chemical properties are the ubiquitous metal-organic frameworks, covalent organic frameworks, dense coordination polymers, and molecular frameworks. Many can respond to stimulation by displaying structural responses and changes in properties that range from counter-intuitive to thermodynamically forbidden. In that, they share large similarities with metamaterials, which are engineered to generate properties not found in "normal" materials. We review here the surprising behavior of these meta-MOFs and other framework materials that display properties "beyond" ( $\mu \varepsilon \tau \dot{\alpha})$ the boundaries of common crystalline materials.
\end{abstract}

Keywords: metal-organic frameworks, framework materials, metamaterials, adsorption, mechanical properties, thermal expansion

\section{Introduction}

Metamaterials are materials with outstanding properties defined by a periodic lattice arrangement, which by the specific combination of composition and geometric distribution are greater than a simple sum of their parts [1, 2]. The precise

Email addresses: fx.coudert@chimieparistech.psl . eu (François-Xavier Coudert), jack.evans@tu-dresden.de (Jack D. Evans) 
lattice structure of metamaterials can be engineered to influence incident electromagnetic and vibrational waves, either by absorbing, enhancing or bending waves, in order to produce phenomena rarely exhibited by natural materials. For example, several photonic crystals can produce a negative refractive index [3] and a zinc blende-like macroscopic network can generate a negative effective bulk modulus [4]. These interesting phenomena have enabled researchers to design entirely novel devices, which at first seem to belong to the world of fantasy literature, including invisibility and unfeelability cloaks [5, 6, 7].

Metamaterials challenge state-of-the-art manufacturing as features of these complex lattice structures are ideally smaller than the wavelength of corresponding incident waves, whether they are electromagnetic or elastic [8, 9]. Despite the complexity of fabricating these materials several elegant examples have been realized. For example, a two-dimensional lattice of concentric cylinders featuring split-ring resonators was fabricated on the millimetre scale, Figure 11 . This structure was demonstrated to act as a invisibility cloak for microwaves, however, the invisibility was imperfect due to material absorption and other approximations [10]. Advanced three-dimensional laser lithography has also enabled the production of once hypothetical mechanical metamaterials [11]. This technology was used to construct a diamondoid structure displayed in Figure $1 \mathrm{~b}$ with connections as small as $0.55 \mu \mathrm{m}$ which is expected to have a ratio of bulk modulus to shear modulus of 10000 [12]. Materials with extremely large bulk modulus and low shear modulus are special mechanical metamaterials; solids that also act as fluids [13].

Similar to these optical and mechanical metamaterials, many coordination frameworks and metal-organic frameworks (MOFs) are reported to exhibit exotic physical properties that are rarely observed in nature [14]. Here we will outline the behavior and applications of seminal examples of metamaterial MOFs (meta-MOFs), from the Greek $\mu \varepsilon \tau \alpha$, which means "beyond". Interestingly, many of the structural features observed in mechanical metamaterials are also found in meta-MOFs, such as bending and buckling building units and dynamic topological arrangements (Figure 2). We define meta-MOFs as crystalline framework materials which exhibit unusual behavior not found, or rarely observed, in conventional crystalline materials (e.g., dense oxides). This behavior, as with metamaterials, is attributed to the specific arrangement of the material's nanoscale building blocks into a periodic framework.

The unique properties exhibited by meta-MOFs include similar mechanical properties to that observed in flexible mechanical metamaterials [2], as well as anomalous thermal properties. In general the displacement and response of con- 
a

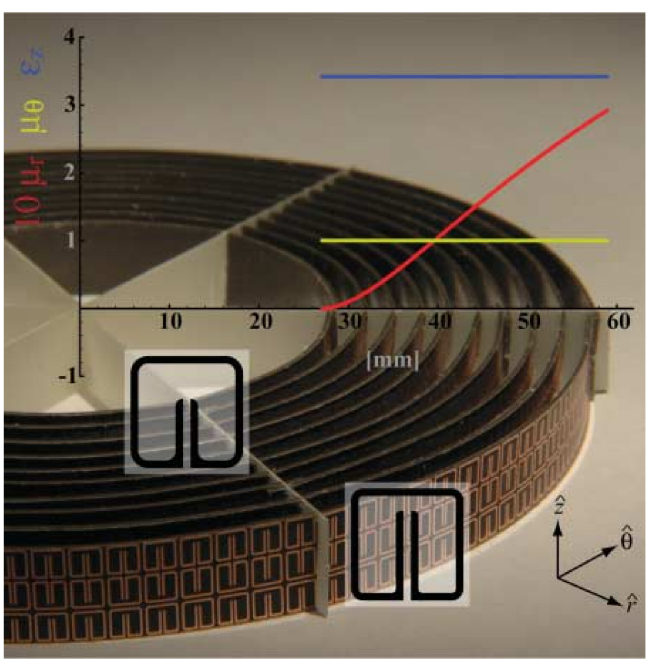

b

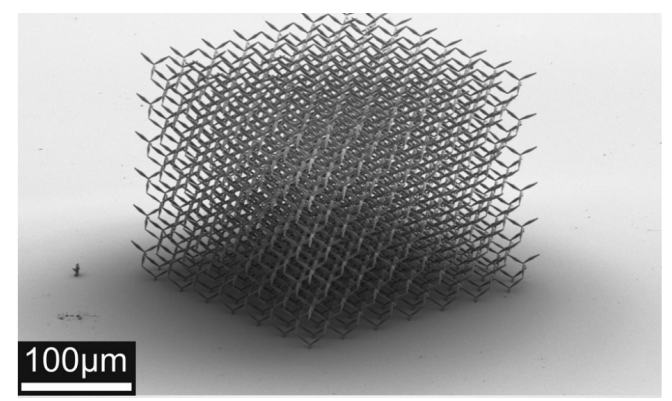

Figure 1: (a) Two-dimensional structure of a microwave cloak illustrating the structure of the splitring resonator features. This includes a plot showing the material parameters of permeability $(\mu)$ and permittivity $(\varepsilon)$. (b) Electron micrograph of a mechanical metamaterial with extremely large bulk modulus and low shear modulus fabricated by laser lithography. Reproduced with permission from Refs. 10 and 12 
metamaterials

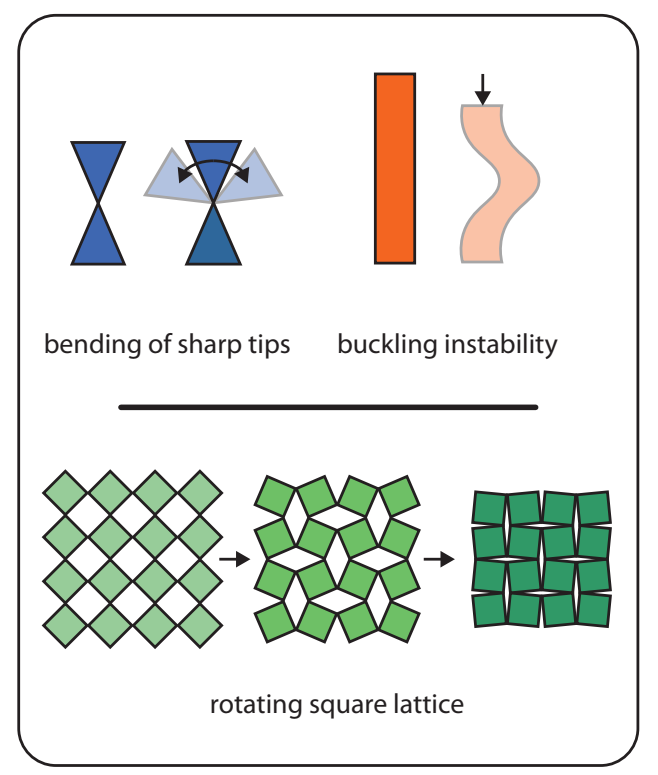

meta-MOFs

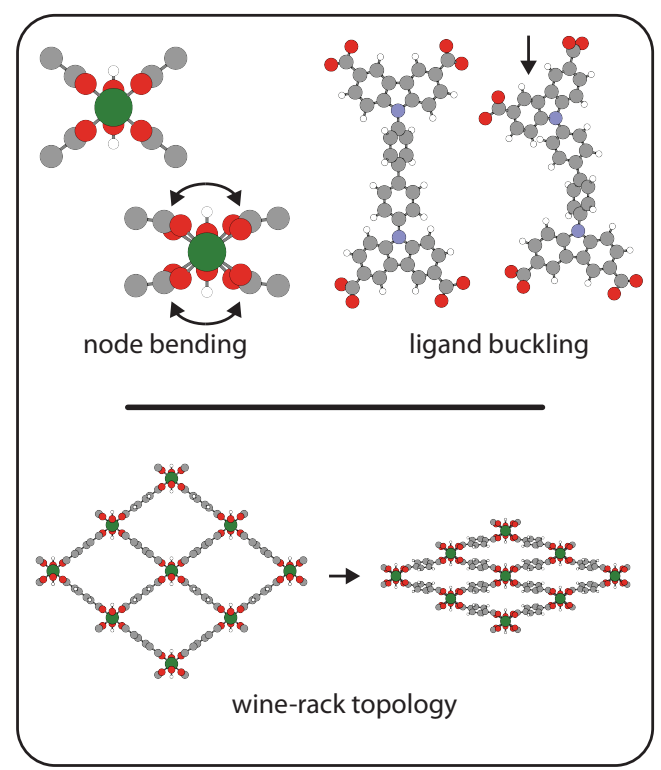

Figure 2: Local and framework features that are used in the construction of mechanical metamaterials, and similar motifs which are observed in meta-MOFs. 
ventional metamaterials is macroscopic, however, the properties of meta-MOFs occur at the microscopic molecular scale, where the "building blocks" of the lattice range in size from a single cation to a molecule. The nanoscale structure of meta-MOFs therefore allows access to behavior, such as negative thermal expansion, which is difficult to engineer in micro or macro architectures [15]. Moreover, the nanoporous (or mesoporous) structure of many meta-MOFs opens a rather unique approach of guest adsorption for the generation of deformation and stresses within a framework. Importantly, this growing research area leverages important concepts of mechanics and thermodynamics, including fundamental theories of elasticity and adsorption [16].

In this review we will highlight seminal examples of meta-MOFs which display extraordinary thermal, mechanical and adsorption properties. Subsequently, we will briefly cover potential applications, where these materials can permit exceptional energy absorption and state-of-the-art gas storage.

\section{Physical properties: thermal and mechanical anomalous behavior}

We first describe here framework materials that respond in an unusual manner to external physical stimuli. While traditional metamaterials are often described for their response to light and other electromagnetic waves (such as negative index of refraction materials), the most notable anomalous behavior of framework materials, to date, is in response to external constraints of temperature and pressure.

\subsection{Negative thermal expansion}

The first class of meta-MOFs display negative thermal expansion (NTE), i.e., whose volume shrink upon an increase in temperature: $(\partial V / \partial T)_{P}<0$. This is in contrast to the thermal behavior of most "normal" dense materials, which expand upon heating, and so negative thermal expansion is often called an "unusual" or a "rare" physical property, "limited to certain types of structures" [17]. Likely the most familiar example, taken from undergraduate thermodynamics textbooks, is that of liquid water between 0 and $4^{\circ} \mathrm{C}$ - and also hexagonal ice! This phenomenon occurs more readily, however, in solids of various types. Including tetrahedrally bonded crystals at low temperature (such as $\mathrm{Si}$ and $\mathrm{Ge}$ ), $\beta$-quartz, some ceramics and zeolites with framework structures and inorganic glasses. For a review of these different families of NTE materials, we direct the reader to Refs. 17, 18, and 19. NTE materials are actively sought after, with a particular focus on materials that feature NTE with a particularly large amplitude, in an isotropic 
manner, or for a wide temperature range. The gold standard NTE material is zirconium tungstate, $\mathrm{ZrW}_{2} \mathrm{O}_{8}$, [20] a cubic oxide that displays isotropic negative expansion from 0.3 to $1050 \mathrm{~K}$. For $\mathrm{ZrW}_{2} \mathrm{O}_{8}$, the volumetric coefficient of thermal expansion,

$$
\alpha_{V}=\frac{1}{V}\left(\frac{\partial V}{\partial T}\right)_{P}
$$

is $-7.2 \times 10^{-6} \mathrm{~K}^{-1}$, which is quite high.

Beyond the beauty and rarity of this phenomenon, negative thermal expansion is desirable for specific applications. In fact, the negative expansion coefficient is not directly sought after for its sign in itself but because it can be used, in combination with a positive thermal expansion material, in order to produce a composite material with controllable thermal expansion. In particular, such composites are a way to produce zero thermal expansion (ZTE) materials, whose volume is unchanged upon heating or cooling. Single-phase ZTE materials are extremely rare, but are desirable in the design of high-precision instruments and devices. They can also be used for medical applications, for bio-implants and as teeth fillings where the mismatch in thermal expansion between tooth and restorative material can create local stress and lead to failure [21].

It is an interesting fact that negative thermal expansion appears to occur at a somewhat higher rate in framework materials. This is true, in particular, of several families of zeolites, [22, 23] such as chabazite, ITQ-4 [24], ITQ-1, ITQ-3, SSZ23 [25], Mg-doped $\mathrm{AlPO}_{4}-17$ [26] and hydrated HZSM-5 [27]. This feature was originally predicted by lattice dynamic calculations [28], before later experimental confirmation. It was rationalized by the occurrence of transverse vibrations of the bridging oxygen atoms between two rigid polyhedrons, or cooperative motions of linked quasi-rigid polyhedral units (so-called "rigid-unit modes"). Furthermore, it appears from several recent reports that other framework materials, and in particular metal-organic frameworks, also readily display negative thermal expansion. This was reported in the archetypal MOF-5, with a linear thermal-expansion coefficient of $-16 \times 10^{-6} \mathrm{~K}^{-1}$ from 4 to $600 \mathrm{~K}$ [29, 30, 31]. It later surfaced that several other MOFs display that same behavior, [32, 33, 34] as well as covalent organic frameworks [35]. In other cases, the thermal expansion is overall positive, but present as a highly anisotropic response of the material to temperature changes, as for HMOF-1 [36].

This relatively common occurrence of NTE in MOF materials has been studied in detail on specific cases, such as MOF-5 [37], and it boils down to the nature of the framework building blocks and their interactions. In a simple dense material 


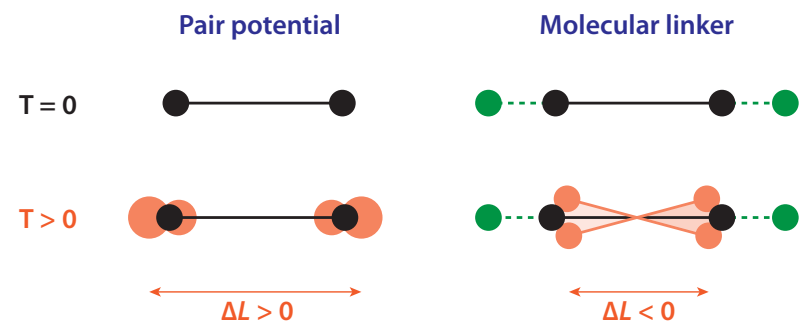

Figure 3: Simple dense materials based on pair interactions display positive thermal expansion due to anharmonicity of the pair interaction potential. Framework materials, however, show very different vibrational modes, which produce a shortening of the distance between nodes.

based on pair interactions, positive thermal expansion arises primarily from the anharmonicity of the pair interaction potential: vibrations make every bond longer on average, which can propagate in three dimensions to give a volume expansion upon heating. In contrast, in framework materials, the nature of the vibration of molecular linkers is quite different: the modes of lowest frequency (and higher amplitude) are associated with vibration of the linkers outside of its metal-linkermetal axis, which shorten the average metal-metal distance (see Figure 3). This local shortening upon heating of the node distances can be propagated to a threedimensional network, depending on the material's topology. This explains the fact that NTE is quite common in framework materials and MOFs. This approach can be formalized, in the quasi-harmonic approximation of thermal expansion, by studying the phonon modes of a crystal and their respective Grüneisen parameters, which characterize their contribution to thermal expansion - with a particular focus on low-frequency modes. This confirms that MOFs can show NTE even in the harmonic regime, because their behavior is dominated soft vibration modes, while for "conventional" dense materials thermal expansion is dominated by the anharmonicity of pair interactions.

Finally, we note that due to their versatile chemistry and their open pore spaces, and using the principles of reticular chemistry, MOFs present one additional advantage in the search for materials with pronounced NTE: their thermal response can be modulated or tuned [38]. This can be achieved, for example by the presence of a controlled amount of guest molecules, such as for the framework material cocrystal analogue $\mathrm{Zn}\left[\mathrm{Ag}(\mathrm{CN})_{2}\right]_{2} \cdot x \mathrm{AgCN}$, a cocrystal with two weakly interacting crystalline phases [39]. This guest-dependent control of the thermal expansion coefficient was observed for guest molecules inside the nanoporous onedimensional channels of a MOF [40]. The thermal behavior of a framework material can also be tuned by functionalization, for example by the addition of alkoxy 
side chains to the organic linker of a MOF [33]. It was also demonstrated that, for a given chemical composition (metal center and organic linker), the topology of the material can be used to tune the thermal expansion, in both sign and magnitude. Bouëssel du Bourg et al.[41] predicted, using molecular simulation, that ZIF materials can exhibit thermal expansion coefficients between $-92 \times 10^{-6} \mathrm{~K}^{-1}$ and $+64 \times 10^{-6} \mathrm{~K}^{-1}$ depending solely on their topology, as depicted on Figure 4 .

Recently, it was demonstrated by Cliffe et al.[43] that controlled introduction of defects in a MOF can also lead to changes in its thermal properties. Incorporation of correlated vacancy defects within the UiO-66(Hf) framework was shown to produce a thermally-densified hafnium-based framework that exhibits a record-holding isotropic negative thermal expansion, for a MOF, with $\alpha_{V}=$ $-97 \times 10^{-6} \mathrm{~K}^{-1}$.

\subsection{Negative linear compressibility}

In addition to temperature, the application of mechanical pressure (or in other terms, stress or load) is another physical stimulus that can generate counter-intuitive responses from a framework material. Dissimilar to heating, it is impossible for the material to expand upon isotropic compression, i.e. its compressibility $\kappa=$ $-(1 / V)(\partial V / \partial P)_{T}$ must be positive, a condition required for mechanical stability. It is possible, however, that a material expands along one or more directions during this volume compression. This phenomenon is called negative linear compressibility (NLC), and it is a rare behavior [44]. Even less common is the expansion in two different crystallographic directions (necessarily accompanied by a massive contraction of the third), a phenomenon for which some authors have coined the term negative area compressibility (NAC) [45, 46]. Like all materials with anisotropic, tailored mechanical responses, NLC materials can find applications as pressure sensors, nano-actuators (such as artificial muscles) and switches.

There are several microscopic mechanisms by which an NLC may occur in a material, including ferroelasticity (where the NLC is associated with a phase transition), networks that can tilt, or feature helices. Three such examples are depicted in Figure 5. We refer the reader to the excellent review by Cairns et al. in Ref. 44 for a detailed description of these mechanisms. We focus here on the occurrence of NLC in framework materials, where the origin of the mechanical response is linked, for the most part, to the topology of the material. The framework acts like a macroscopic truss, where the organic linkers are the rigid struts, and metal centers act as hinges - and flexibility arises from the deformation of the metal coordination environment [50, 51]. The two most common frameworks type that inherently display NLC are the "wine rack" (somewhat common among MOFs) 


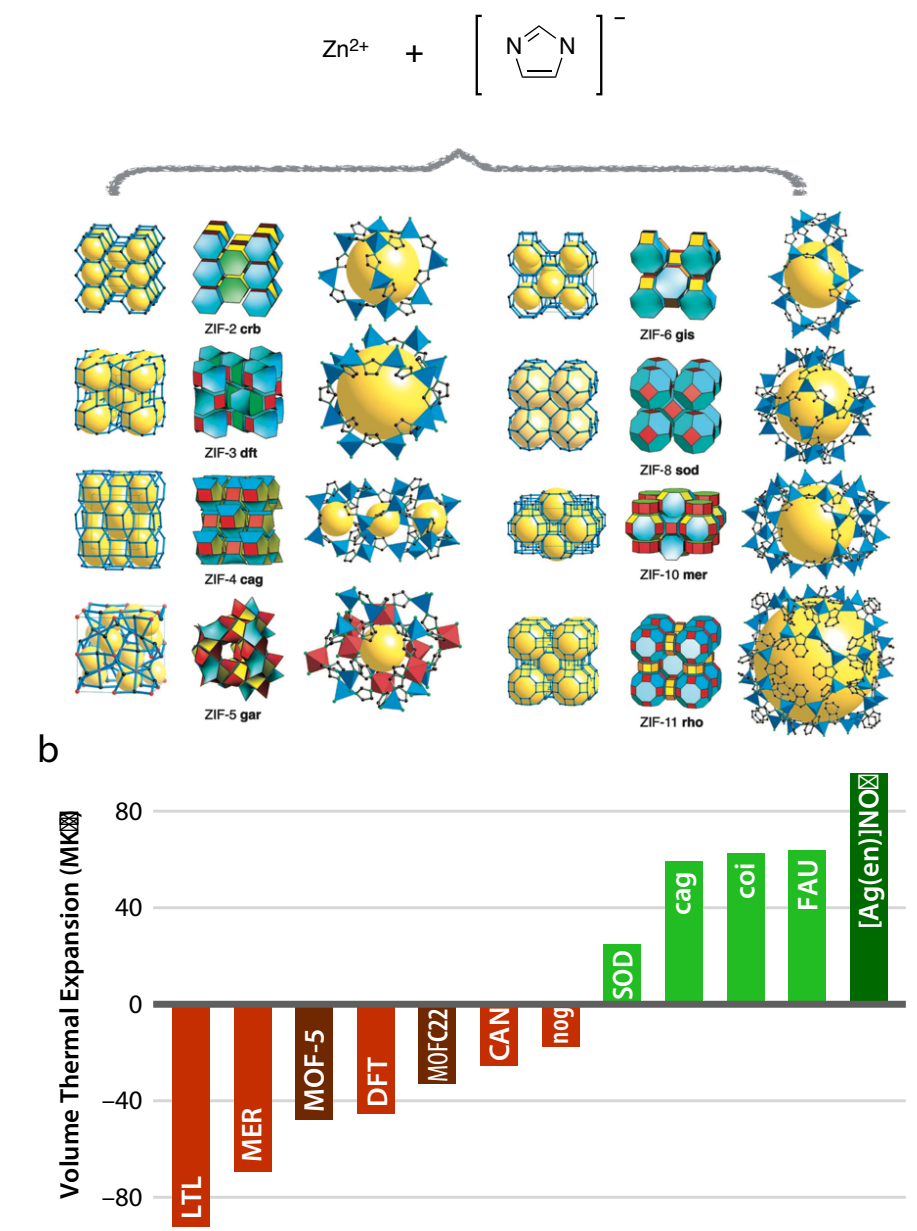

Figure 4: (a) The molecular components of ZIFs which can generate diverse structural topologies. (b) Thermal expansion coefficients of ZIF frameworks with varying topology (LTL, MER, DFT, CAN, nog, SOD, cag, coi, and FAU). Values for some other MOFs are reported for comparison: MOF-5, MOF-C22, and [Ag(en)]NO $\mathrm{N}_{3}$. Reproduced with permission from Ref. 42 and Ref. 41 

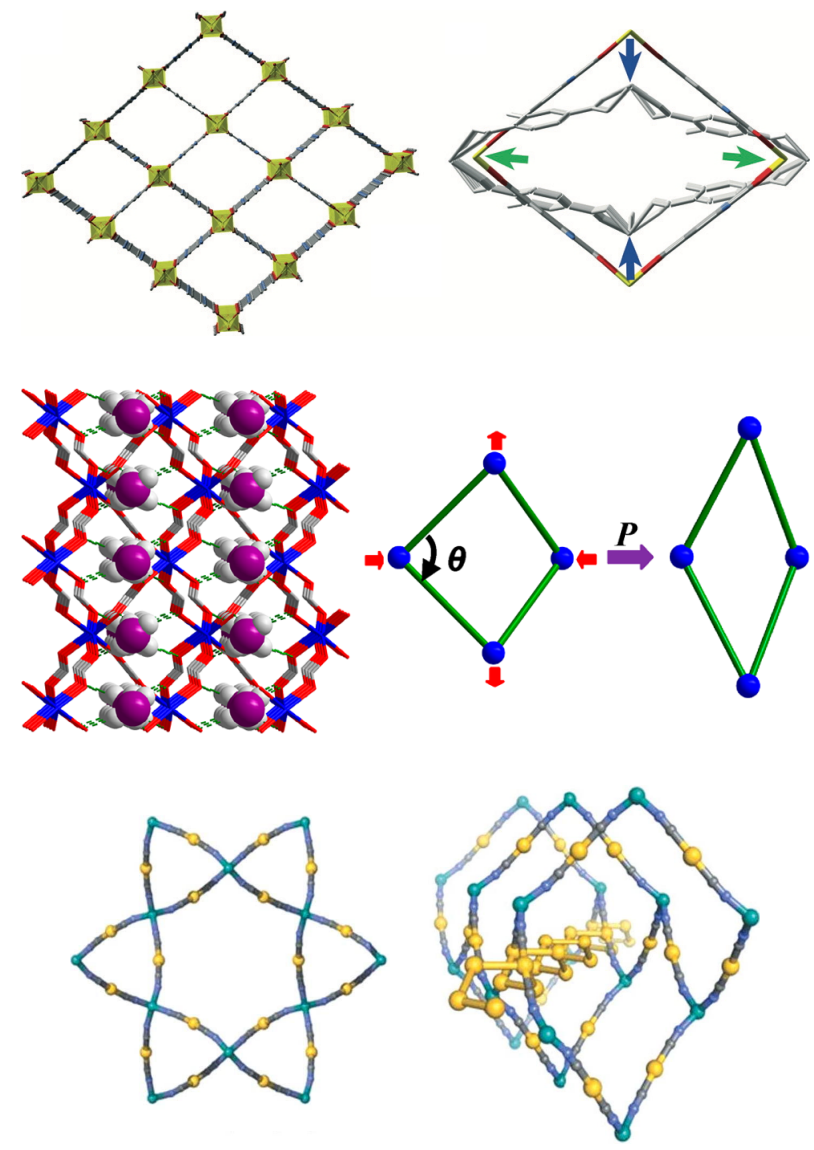

Figure 5: Framework materials featuring negative linear compressibility. Top to bottom: MIL-53, $\left[\mathrm{NH}_{4}\right]\left[\mathrm{Zn}(\mathrm{HCOO})_{3}\right]$ and $\mathrm{Zn}\left[\mathrm{Au}(\mathrm{CN})_{2}\right]$. Reproduced with permission from Refs. 47, 48 and 49

and "honeycomb" networks. Examples of materials of these topologies featuring NLC include: the archetypal MIL-53 [52], whose breathing transition (see Section 3] is also associated with NLC [47]; the distorted wine rack framework in $\left[\mathrm{NH}_{4}\right]\left[\mathrm{Zn}(\mathrm{HCOO})_{3}\right] \mathrm{MOF}$ [48]; the $\mathrm{Zn}\left[\mathrm{Au}(\mathrm{CN})_{2}\right]$ framework with honeycomb structure [49]; and calcium fumarate trihydrate, a one-dimensional coordination polymer [53]. There is also a know MOF with large negative area compressibility, $\mathrm{Zn}\left(\mathrm{CH}_{3} \mathrm{COO}\right)_{2} \cdot 2 \mathrm{H}_{2} \mathrm{O}$, a hydrogen-bonded $2 \mathrm{D}$ supramolecular coordination complex [54] where the NAC arises from cooperative intra-layer coordination and hydrogen-bonding interactions, as well as inter-layer van der Waals forces.

Furthermore, like the thermal expansion coefficient, compressibility in MOFs can in principle be tuned by modifications of the framework or inclusion of guest 


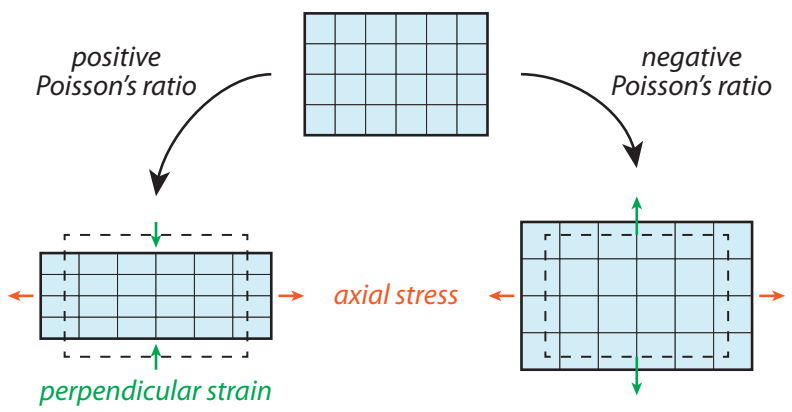

Figure 6: Illustration of the sign of a material's Poisson's ratio.

molecules, although reports in that area are still rather scarce. Cai et al.[46] showed that it was possible to tune the large-scale negative area compressibility in $\mathrm{Zn}(\mathrm{L})_{2}(\mathrm{OH})_{2}$ ( $\mathrm{L}=4$-(1H-naphtho[2,3- $d]$ imidazol-1-yl)benzoate) by exchanging guests adsorbed from hydrostatic fluids.

\subsection{Other mechanical surprises}

The behavior of framework materials under pressure is rich, and their response to mechanical stimuli is extremely varied. Pressure is not a scalar component, like temperature, and can thus be applied in an isotropic or an anisotropic manner; and the response of the crystal can also be anisotropic [55]. Pressure can be applied directly, by techniques such as nanoindentation, or through a pressure-transmitting fluid [56]. Moreover, in the case of nanoporous solids, the fluid can be either nonpenetrating, or enter the pores of the material - in which case the response will be complex, due to both the fluid intrusion inside the pores [57, 58, 59] and the mechanical stress on the framework. Nonlinear phenomena such as pressure-induced structural transitions and amorphization are relatively common in MOFs. Examples include the pressure-induced cooperative bond rearrangement in ZIF-zni [60], proton transfer in ZAG-4 [61, 62], phase transitions induced by polar fluid intrusion (water, methanol, ethanol) in $\mathrm{Zn}(\mathrm{CN})_{2}$ [63] and indentation-induced bond rearrangements of a Er-based MOF [64].

Even in the linear elastic regime, MOFs have potential to show unusual mechanical behavior. One of these is the manifestation of auxeticity, i.e. the presence of a negative Poisson's ratio [65]. "Normal" materials have a positive Poisson's ratio, meaning that under uniaxial tension, they shrink in the perpendicular directions (think of rubber, which gets thinner as it is stretched). Auxetic materials, on the other hand, expand in one or two of the perpendicular axes (see Figure 6). Auxeticity is present for example in porous foams or artificial macrostructures[66], 

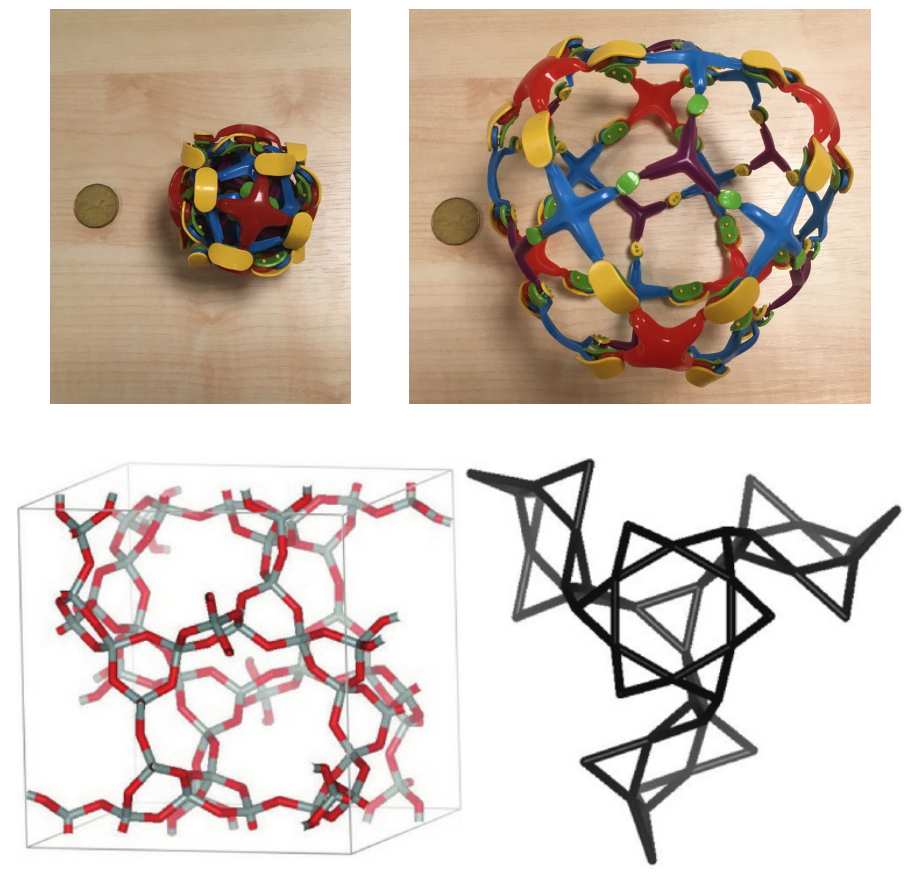

Figure 7: (top) Hoberman Twist-O,[74] a variant of the Hoberman sphere, a macroscopic structure with complete auxeticity (loonie for scale). (bottom) JST zeolite framework, featuring complete auxeticity, and its characteristic assembly of four "stars of David" into a tetrahedron. Reproduced with permission from Ref. 75 .

but is relatively rare in crystalline materials [67, 68]. Among the known auxetic framework materials, zeolites have probably been the most studied [69, 70]. More recently, several MOF frameworks have also been shown to present auxeticity, including MIL-140[71], ZIF-3[72] and ZIF-4[73].

All these materials display auxeticity in a few directions of space, but not all. The occurrence of a negative Poisson's ratio in all directions of space is even rarer: for a tension applied in any direction of space, it requires expansion in all perpendicular directions. This phenomenon, called complete auxeticity, can be introduced by design in macroscopic structures such as the Hoberman sphere (see Figure 7]; it is, however, extremely rare in single crystals. Siddorn et al.[75] proposed a classification for auxeticity, and analyzed the experimental elastic constants of 471 crystalline materials. They showed that partial auxeticity is present in $37 \%$ of cases. In stark contrast, average auxeticity (negative average of the Poisson's ratio over all directions) is only present in one compound, $\alpha$-cristobalite. Moreover, no material in the experimental database was found to present complete auxeticity. 
The same authors surveyed by molecular simulations two hundred pure silica zeolites, and predicted the first known example of complete auxeticity in the JST zeolite framework (see Figure 7). The characteristic structural motif of tetrahedra featuring four "stars of David", which forms the JST framework, produces this unique property of complete auxeticity. Given the larger number of know MOF structures than zeolites frameworks, it is possible that several of them feature complete auxeticity - although they have not yet been identified.

\section{Adsorption properties: contraction, expansion and metastability}

The combination of a porous framework and unique large-scale flexibility, displayed by many MOFs, can produce interesting responsive behaviors. There are many reports of MOFs, which display significant transformations following the adsorption (or desorption) of gases or liquids. This includes both crystal-tocrystal and crystal-to-amorphous transitions between different phases of the material. These adsorption-induced deformations and transitions in MOFs can be explained with respect to their structures and the relative enthalpy and entropy of guest adsorption. We note that adsorption-induced contraction and expansion of microporous materials, in itself, is a generic phenomenon that has been observed in a wide variety of materials, including microporous carbons, zeolites and MOFs [76].

The flexibility of meta-MOFs, however, permits structural changes on an unprecedented scale upon adsorption, with many materials displaying volume changes of $\Delta V / V \simeq 40 \%$ and higher. These phase transformations occurring under adsorption can also be observed in response to other external forces, such as hydrostatic pressure [77, 78]. The nature of the structural transitions observed is varied, and can include gate-opening, swelling and breathing behavior as illustrated in Figure 8 . The mechanisms for achieving these transitions can involve either a massive transformation of the underlying lattice structure, or changes of orientation of molecular moieties that surround the pore structure [79, 80]. In this section we highlight the behavior of MOFs that can undergo adsorption-induced contraction and expansion.

\subsection{Adsorption-induced contraction}

As described earlier, adsorption-induced contraction is a relatively common phenomenon in porous materials, being the rule rather than the exception [81, 82]. However it occurs on a much larger scale in soft framework materials [83]. This is 
a

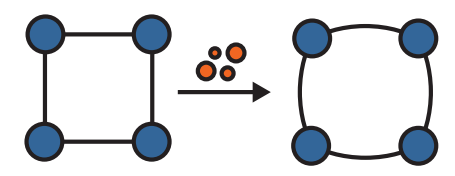

C

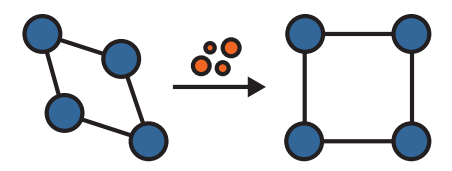

b

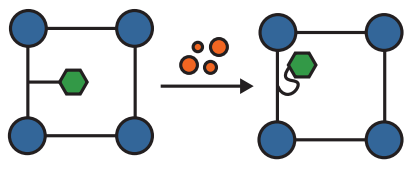

d

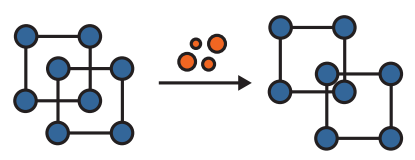

e

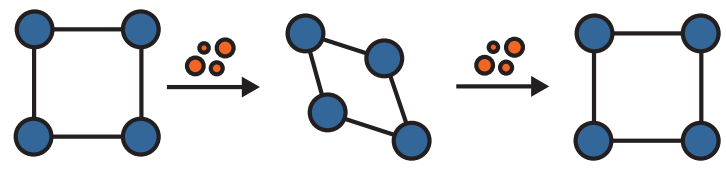

Figure 8: Illustrations of transitions that are induced by adsorption stresses. (a) Swelling, (b) gateopening by ligand dynamics, (c) lattice deformation, (d) lattice displacement and (e) breathing by lattice deformation.

considered a counter-intuitive property, as macroscopic structures tend to follow the inverse trend: think of inflating a tire, or adding water to a dried sponge.

However surprising it may be, at the microscopic scale adsorption can provide significant internal stress to a porous framework, which can lead to either shrinking or expansion of the material. The most common behavior is that of a contraction at low to intermediate loading (due to weakly attracting interactions between the adsorbate and host framework), followed by expansion of the material at high loading. Neimark and coworkers pioneered the concept of adsorption stress and demonstrated a rigorous theoretical description of this phenomenon [82]. For some reference the magnitude of this stress, for Xe adsorption in the gas phase, at $180 \mathrm{~K}$ on the zeolite $\mathrm{CaNaX}$, is approximately $20 \mathrm{MPa}$ (Figure 9). In very confined spaces, at low temperature or in the liquid phase, this stress has been measured to go up to $\simeq 1 \mathrm{GPa}$ [84]. While for many materials this only produces strains on the order of $10^{-3}$ to $10^{-2}(0.1 \%$ to $1 \%$ change in volume) soft porous crystals, however, are much softer than conventional porous materials [85, 52] thus this relatively small stress can produce greater changes in structure.

Interestingly, it was demonstrated more recently that soft framework materials 

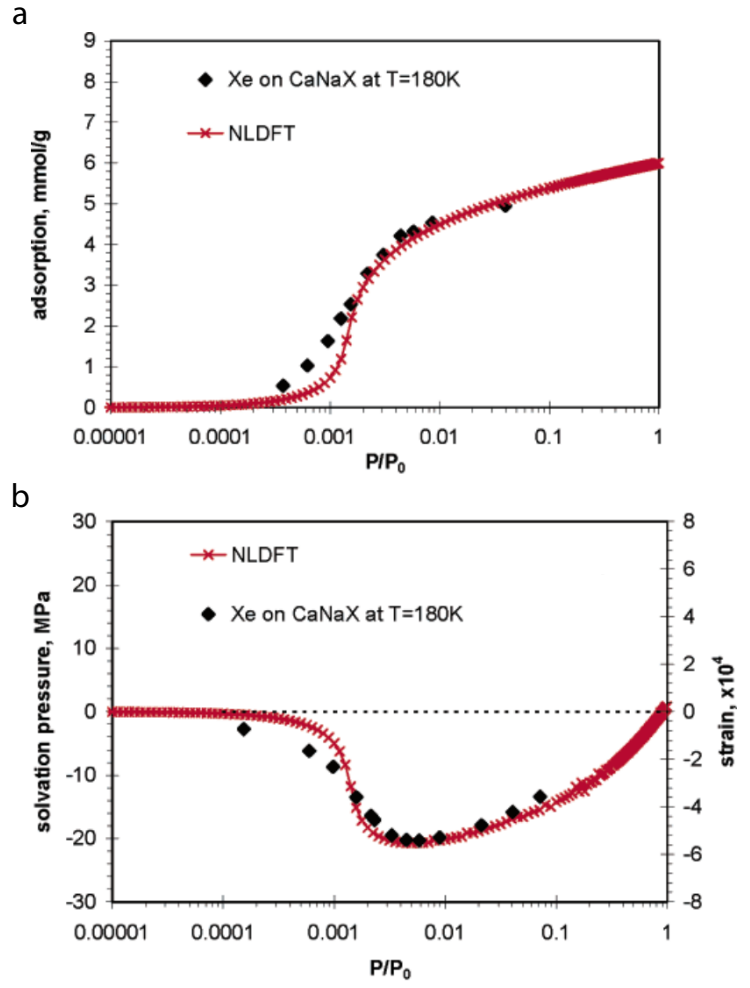

Figure 9: (a) Experimental (points) and calculated (line) adsorption isotherms of xenon on zeolite $\mathrm{CaNaX}$ at $180 \mathrm{~K}$. (b) Experimental strain (points, right vertical axis) and calculated solvation pressure or adsorption stress (line, left vertical axis) as a function of the pressure. Reproduced with permission from Ref. 82 .

can also exhibit significant softening in parallel with this adsorption-induced contraction. A theoretical study of methane adsorption in model systems of simple geometries (slit pores and diamond-shaped channels) demonstrated a nonmonotonic change in the elastic constant upon fluid adsorption [86]. For the slit pore system the contraction of the pore volume at low loading is accompanied by a lowering of the Young's modulus, in the direction perpendicular to the pore walls, producing a softer material. This behavior was also observed in the analogous diamond-shaped pore system. The changes to the elasticity of these systems is much greater than changes to the pore geometry. For an elastic modulus of $10 \mathrm{GPa}$, representative of many MOFs, the variation of mechanical properties is up to $5 \mathrm{GPa}$ (for the change in $C_{33}$ in the slit pore system), which is much larger than contraction in pore size $(0.6 \AA$ for a slit pore of $15 \AA)$. This was further exemplified by careful 
examination of molecular dynamics trajectories of a ZIF with nog topology. For this material, the softest elastic deformation mode, $\lambda_{\min }$, showed softening by a factor of two at low methane loading. Curiously, this study found a similar material, ZIF-8 with sod topology, does not show such a behavior. The softening of porous materials by adsorption is thus potentially widespread, but not universal: it appears that specific materials such as ZIF-8 are resistant, possibly due to their topology.

Experimentally, the softening of materials upon the application of external pressure can be identified by careful analysis of the pressure dependence of the bulk modulus $\left(K^{\prime}\right)$. A negative $K^{\prime}$ indicates that a framework becomes more compressible with increasing pressure and this is considered anomalous for conventional solids. Indeed, following contraction a material is more dense than the original structure, and denser phases are usually stiffer. Chapman et al. suggested negative $K^{\prime}$ values may, however, be relatively widespread in porous materials, where small volume reduction is not sufficient to result in unfavorably close contact of atoms [87]. As a result of negative $K^{\prime}$ values, a number of open framework materials can exhibit large changes in volume, outside of the elastic regime, because of a "snowball" effect. This provides a pathway for drastic changes in pore volume either by transitions to other crystalline phases of higher density, or by catastrophic pressure-induced amorphization [88].

However, adsorption-induced contraction does not always trigger an isotropic or volumetric response, and can induce more exotic phenomena, such as a chiral transformation in the framework. Zhang et al. reported that a chiral deformation of the achiral MOF-5 could be induced by immersion in $N$-methyl-2-pyrrolidone (NMP), an achiral solvent [90]. Following this study we conducted molecular simulations identifying the specific adsorption of NMP within the pores of MOF5, demonstrated in Figure 10, which is responsible for this chiral deformation [89].

Finally, we note that all the examples discussed above relate to physical adsorption of guest molecules in a porous structure. However in some cases, even small molecules can ingress in formally nonporous dense framework materials. Recently, Goodwin and coworkers described negative hydration expansion (NHE) in zirconium tungstate, $\mathrm{Zr}_{2} \mathrm{~W}_{2} \mathrm{O}_{8}$. Though nonporous, this structure can be reversibly hydrated to $\mathrm{Zr}_{2} \mathrm{~W}_{2} \mathrm{O}_{8} \cdot \mathrm{H}_{2} \mathrm{O}$, transforming to a disordered phase that is $20 \%$ more dense [91]. Examination of the correlated translation, rotation and distortion of $\mathrm{ZrO}_{6} / \mathrm{WO}_{4}$ study identified "spaghetti-like" displacements of a $\mathrm{W}-\mathrm{O}-\mathrm{W}$ network which are responsible for NHE in this material. The same modes are also involved in the strong negative thermal expansion of $\mathrm{Zr}_{2} \mathrm{~W}_{2} \mathrm{O}_{8}$. 

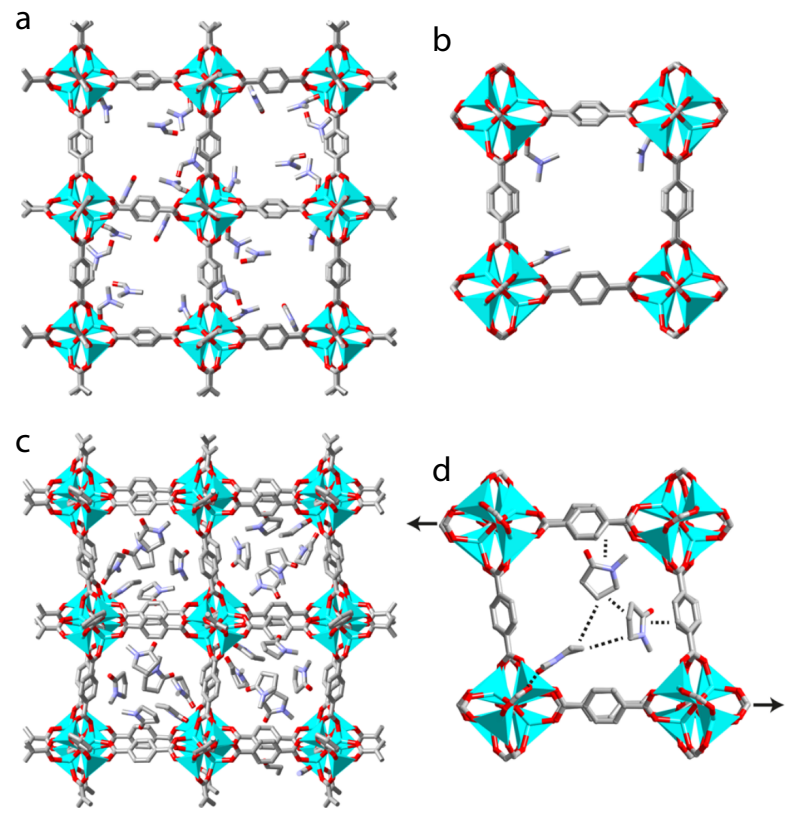

Figure 10: (a, b) DFT optimizations for a widely used solvent molecule, dimethylformamide, and (c,d) NMP within the MOF-5 structure. (a,c) Extent of chiral induction on the framework structure. (b,d) The distinct local ordering of guest molecules. Reproduced with permission from Ref. 89

\subsection{Adsorption-induced expansion}

As described in the previous section, unit cell changes induced by adsorption follow a nonmonotonic behavior, where low guest loading may produce contraction and softening, but at higher loading porous materials often expand, dilating to accommodate the adsorption of more guest molecules [92].

Gate opening - In many cases this behavior results in a small, continuous expansion in pore volume at high pressure and loading. However, some materials will show a gate-opening process, where at a given gas pressure the material suddenly adsorbs a greater amount - resulting in a steep step in the gas adsorption isotherm. The prototypical gate-opening process was reported by Kitaura et al. for a porous coordination-polymer comprising of interdigitating two-dimensional sheets [93]. From $\mathrm{N}_{2}$ adsorption data at $77 \mathrm{~K}$ this interdigitated structure appears nonporous, however in adsorption experiments at $298 \mathrm{~K}$ the structure shows an sudden increase in adsorption at a specific guest-dependent pressure, as depicted in Figure 11. This transition corresponds to the transformation of the material 
from a non-porous phase, with BET surface area of $24 \mathrm{~m}^{2} \mathrm{~g}^{-1}$, to a porous phase with an estimated surface area of $320 \mathrm{~m}^{2} \mathrm{~g}^{-1}$. This first-order phase transition is achieved by displacement of the sheets, held together by $\pi-\pi$ interactions in the evacuated structure, thus producing a porous structure.

Many other structures have been reported to display this gate-opening adsorption process. The main microscopic framework features which can result in gateopening include lattice displacement, movement of framework features and deformation of the metal node. For example, the two-dimensional layers of ELM-11, similar to the material of Kitaura et al., separate at given guest pressure and temperature producing a microporous system and a gate-opening transition [94]. This system has been extensively studied to provide insight into responsive adsorption phenomena [95, 96, 97].

A family of isostructural materials named DUT-8 (comprised of transition metal paddlewheel units with 1,4-benzenedicarboxylate and 1,4-diazabicyclo[2,2,2]octane ligands) shows significant deformation of the paddlewheel unit which permits a large degree of flexibility [98, 99]. DUT-8(Ni) exhibits gate-opening adsorption processes where a complete collapse after solvent removal is reversible following the adsorption of gas at a specific pressure and temperature.

Local framework dynamics - While most the examples we have discussed above manipulate changes in density to affect the pore volume, rotational dynamics of the framework can also provide a similar adsorption phenomenon without change in the total unit cell volume. This has been widely reported for materials of the ZIF-8 [100] family, which features a swing effect of imidizolate sub-units allowing for accommodation of more guest molecules and a relatively small step in the gas adsorption isotherm of $\mathrm{N}_{2}$ at $77 \mathrm{~K}$ as demonstrated in Figure 12 [101].

As the deformations and dynamics responsible for these transitions occur on a molecular level, it enables tuning this expansion phenomenon by chemical approaches. The swing effect of ZIF-8 can be altered by modifying chemistry of the imidizolate unit, which has a pendant $-\mathrm{CH}_{3}$ group that can be replaced by other chemical moieties. Recently, Chaplais and coworkers reported the impact of different imidizolate functionality [102]. In their work, it was discovered nitrogen adsorption isotherms for the framework composed of $\mathrm{Cl}$ functionality (ZIF-8$\mathrm{Cl}$ ) showed similar behavior to the original ZIF-8 $\left(\mathrm{ZIF}-8-\mathrm{CH}_{3}\right)$, however the Brfunctionalized system (ZIF-8-Br) displayed a rigid response during gas adsorption. Molecular simulations of the flexible materials, $\mathrm{ZIF}-8-\mathrm{CH}_{3}$ and $\mathrm{ZIF}-8-\mathrm{Cl}$, identified that the rotation of the ligand is influenced by the adsorption of $\mathrm{N}_{2}$ but remains unchanged for ZIF-8-Br. The reordering of adsorbed nitrogen molecules responsible for the swing effect [104] is unable to occur ZIF-8-Br as the greater 
a
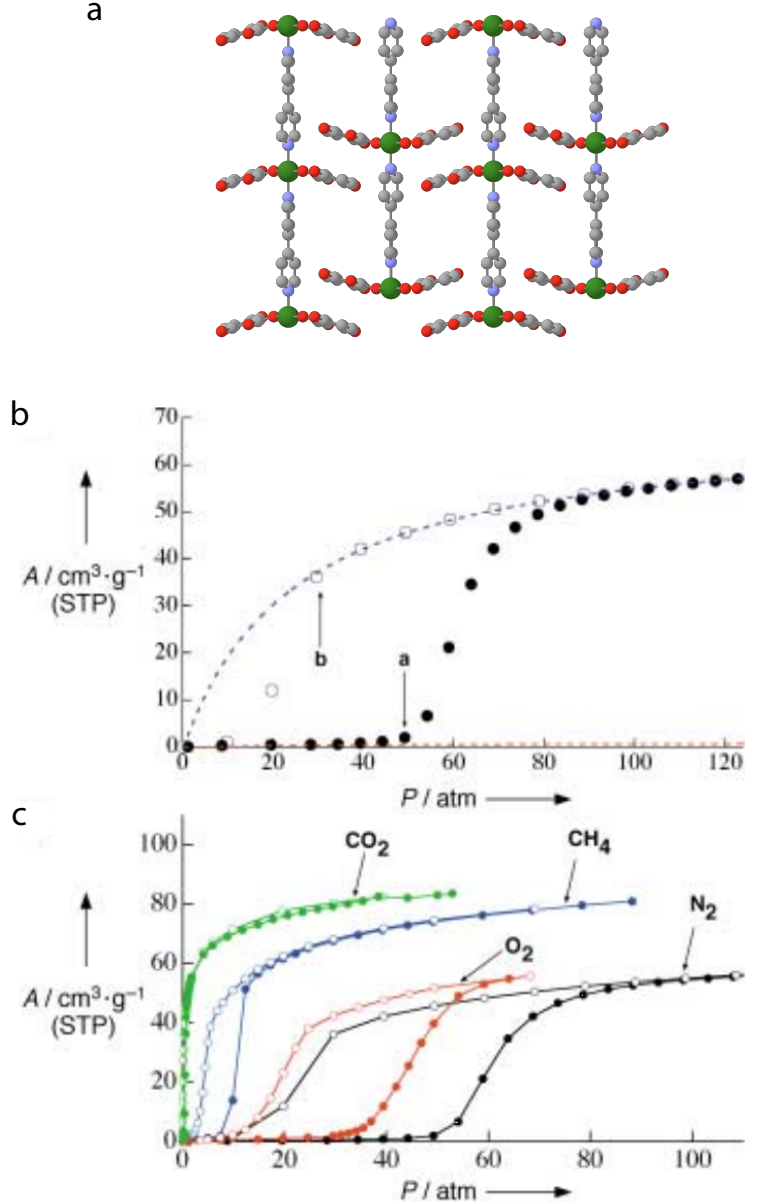

Figure 11: (a) Structure of the interdigitating two-dimensional sheets of $\mathrm{Cu}(\mathrm{dhbc})_{2}\left(4,4^{\prime}\right.$-bpy), with hydrogens removed for clarity; $d h b c=2,5$-dihydroxybenzoate, bpy = bipyridine. (b) Nitrogen adsorption isotherms at $298 \mathrm{~K}$ where the blue and red dashed lines correspond to Langmuir plots fit in the high and low pressure ranges, respectively. (c) Adsorption isotherms of $\mathrm{N}_{2}, \mathrm{CH}_{4}, \mathrm{CO}_{2}$ and $\mathrm{O}_{2}$ at $298 \mathrm{~K}$. Adsorption and desorption is displayed by open and filled symbols, respectively. Reproduced with permission from Ref. 93 
a
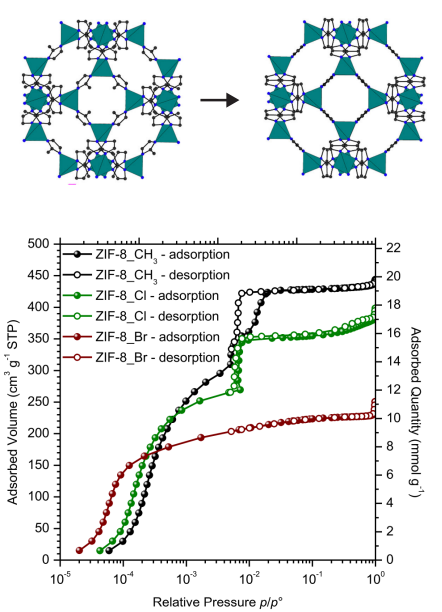

c

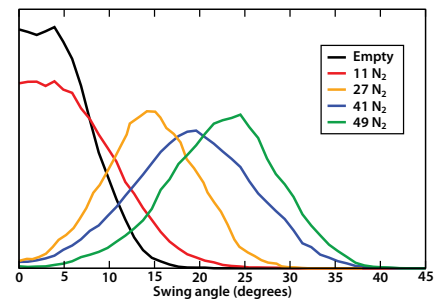

Figure 12: (a) Illustration of the subtle structural change of ZIF-8 by rotation of the ligand subunit, elucidated by high pressure crystallography. (b) Adsorption isotherm for $\mathrm{N}_{2}$ at $77 \mathrm{~K}$ for ZIF-8 analogues. (c) Simulations of the ligand angle distribution for increasing adsorption of $\mathrm{N}_{2}$, demonstrating the ligand swing process. Reproduced with permission from Refs. 101, 102 and 103 
steric size of the Br functionality produces pores which are too small for the reordering to take place.

Tuning of gate opening - Changes of ligand composition are also able to tune the gate-opening pressure in a series of pillar-layer MOFs, structurally similar to DUT-8. Henke et al. described how, in these materials, the substitution pattern of the ligand sub-unit and the bulkiness and chemical nature of the substituents profoundly affect the structure and energetics of the collapsed pore phase and thus the responsive gate-opening behavior [105]. Similarly, DUT- 8 can be produced using a variety of transition metals as inorganic nodes, and the degree of flexibility displayed by DUT- 8 is dependent on the composition of the paddlewheel [106]. For instance DUT- $8(\mathrm{Cu})$ shows rigid behavior and remains open after solvent evacuation, but DUT-8(Zn) will collapse to a different phase and does not expand upon exposure to gas. We note that the underlying chemistry behind the different responses for different metal paddlewheels, as observed in other framework systems [107], is not yet well understood.

Recently, McGuirk et al. reported the affects different metals have on the gateopening behavior of the ZIF-7 framework, a zeolitic imidazolate framework with sodalite (SOD) topology and benzimidazolate ligands [108]. A smaller length (or greater strength) of metal-ligand bonds was observed to be correlated with a shift in gate-opening pressure to higher pressure in these materials. However, considerably longer (or weaker) metal-ligand bonds can produce greater flexibility, permitting the formation of different collapsed pore states which in turn also require greater pressure for gate-opening. It is thus clear that the effect of coordination chemistry on framework flexibility is far from simple, with many questions still open.

\subsection{Metastable transitions}

The expansion and contraction of meta-MOF systems usually occur at stable equilibrium, where the contracted or expanded states correspond to lowest free energy structures. Equilibrium transitions between contracted and expanded phases are responsible for established adsorption processes, as described previously, although some small hysteresis around the transition can be observed [109]. These processes can also occur out of equilibrium, where the material is able to remain in long-lived metastable states and this can result in novel adsorption phenomena.

Tanaka et al. observed a unique kinetic gate-opening process in a flexible porous coordination polymer comprising of interdigitated sheets of cadmium with benzophenone-4, 4'-dicarboxylate and 4, 4'-bipyridyl ligands [110]. Gas adsorption isotherms for this material showed a sudden increase of adsorption gate- 
opening pressures concomitant with a decrease in pressure, as can be seen on Figure 13. This process is interpreted as a delayed onset of the traditional gateopening transition because of the particular kinetic behavior of this material. The authors carefully measured the adsorption kinetics and observed the kinetics for the onset of gate-opening does not follow a simple diffusion limited process. Instead this closed phase is first transformed to an intermediate before an open porous phase and during the formation of this intermediate state gas molecules can only condense on the crystal surface, as the crystal remains nonporous. This is able to explain how intermolecular interactions of the guest molecules govern this process and as such the gate-opening pressures observed are not dictated by diffusion.

The initial report from Tanaka et al. suggests similar kinetically delayed gateopening processes should be observed for other gate-opening materials, when gases lacking strong intermolecular forces are used. In fact three doubly interpenetrated MOFs with wine-rack-like topology have been reported to show a similar kinetic gate-opening process with $\mathrm{N}_{2}$ adsorption [111, 112, 113]. We note that careful analysis of adsorption kinetics is required to ensure the pressure step is due a long-lived metastable state and not caused by inadequate equilibration.

Similar to gate-opening materials, where the collapsed pore state can remain metastable leading to a drop in pressure when opened, there are also breathing materials where the more porous state is metastable and a release of gas is generated upon the transition to a less porous state. This behavior has been named negative gas adsorption (NGA) [114]. At the time of writing, only two materials have been reported which display this phenomenon: a synthetic faujasite zeolite and a highly porous MOF.

In 1969, Riekert reported the $\mathrm{CO}_{2}$ and $\mathrm{C}_{2} \mathrm{H}_{6}$ adsorption on a $\mathrm{HY}$ zeolite, obtained by calcination of $\mathrm{NH}_{4} \mathrm{Y}$ at $400^{\circ} \mathrm{C}$ [115]. The isotherms show spontaneous desorption of the gas when a critical amount of adsorbate is present. This was attributed to a change of equilibrium positions of the cations by the adsorbate leading to a significant change in the adsorption properties and thus desorption [116]. Cation displacement can result in small changes in adsorption properties, however, pore volume changes can produce a much greater change.

The second, and ground breaking material, is DUT-49 which is a MOF constructed from large tetratopic carbazole ligands and copper paddlewheels [117]. This material boasts exception porosity with a BET surface area of $5476 \mathrm{~m}^{2} \mathrm{~g}^{-1}$ and pore volume of $2.91 \mathrm{~cm}^{3} \mathrm{~g}^{-1}$. Investigation of $\mathrm{CH}_{4}$ and $n$-butane adsorption at sub-critical temperatures reveal a drastic breathing transition where there is over a $60 \%$ change in pore volume as displayed in Figure 14a [114]. Breathing tran- 

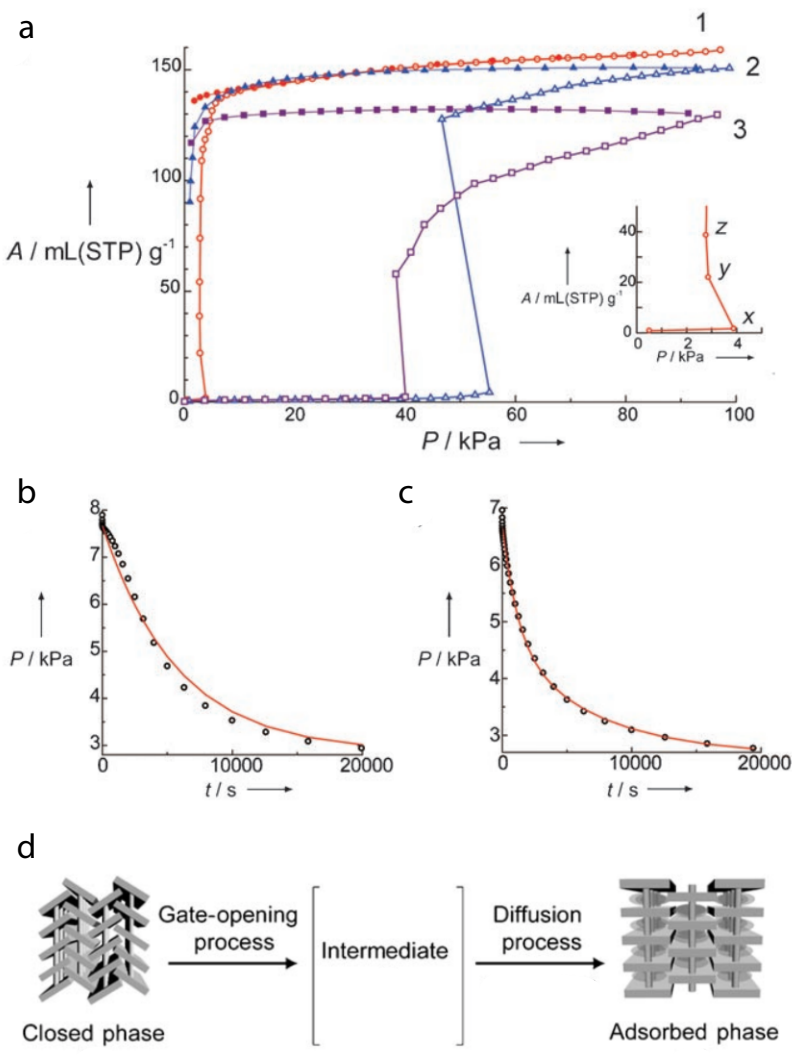

Figure 13: (a) Adsorption isotherms at $90 \mathrm{~K}$ for 1) $\mathrm{O}_{2}$ adsorption, 2) $\mathrm{N}_{2}$ and 3) Ar, in $\mathrm{Cd}$ (bpndc)(bpy) (where bpndc $=$ benzophenone-4,4'-dicarboxylate, bpy=4,4' -bipyridyl). Adsorption is illustrated by open symbols and desorption by filled symbols. The $\mathrm{O}_{2}$ adsorption isotherm at low pressure is displayed inset. Pressure versus time graphs from (b) point $x$ to point $y$ of the inset displayed in (a), and (c) from point $y$ to point $z$. (d) Structural description of the identified kinetic pathway for this gate-opening process. Reproduced with permission from Ref. 110 
sitions as illustrated in Figure 8 e begin with adsorption induced contraction, to a closed pore phase, which at higher loading is followed by adsorption-induced expansion, back to the original open pore phase. Surprisingly, the initial extremely porous phase of DUT-49 remains metastable during adsorption allowing for the pores of the structure to adsorb a significant amount of gas. At the point of NGA the open pore phase has adsorbed much more than is feasible by the closed pore phase and thus this results in a release of gas molecules producing the isotherm profile illustrated in Figure 14b. Detailed in situ measurements and molecular simulation were able to identify the structure of the two phases present in the NGA transition and calculations of their relative enthalpy of adsorption were used to explain the driving force for the massive change in structure. Pore structures with smaller pore size have a substantially stronger affinity for the adsorption of gas than mesopores, like that found in DUT-49. It was demonstrated than the energy gain from adsorption in the low porosity phase offset the energy penalty of structural deformation. As a result this material appears to disobey a general rule of thermodynamics where, at constant temperature, the absolute amount of the adsorbed phase ( $\left.n_{\text {ads }}\right)$ always increases with increasing pressure $(p)$ : $\mathrm{d} n_{\text {ads }} / \mathrm{d} p \geq 0$.

Following this initial study we have continued to explore the process of NGA. Examination of the structural deformation of the ligand sub-unit of DUT-49, using quantum chemistry methods, highlighted a buckling process as depicted in Figure 15 [118]. This buckling motif is also observed in traditional macroscopic metamaterials and enables a sudden and drastic change in the structure of the framework at a critical stress [119]. Recently, an isoreticular analogue of DUT-49 was reported which is observed to be rigid with no breathing or NGA [78]. The analogue, DUT-48, is constructed with a smaller ligand which leads to a smaller pore size. The absence of structural transition in this material is explained due to the greater stress required to buckle shorter beams and a significantly lower adsorption enthalpy difference because the pore size difference between the open pore and deformed pore phase is much less than for DUT-49.

\section{Potential applications}

The unique and exotic responses of meta-MOFs provide access to a number of exciting applications [120]. Traditional mechanical metamaterials have found use in advanced applications such as the deployment of satellite solar panels in space [121]. Many meta-MOFs have similar mechanical properties as metamaterials and thus also similar applications but on a nanoscale. 
$a$

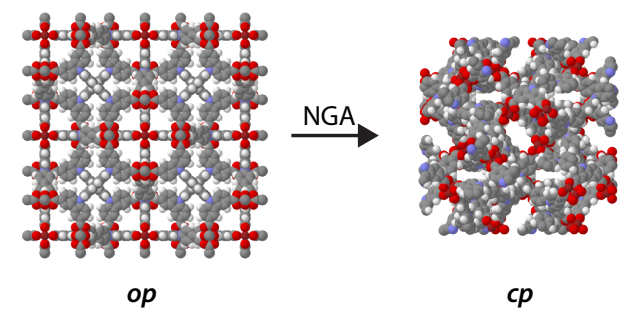

b

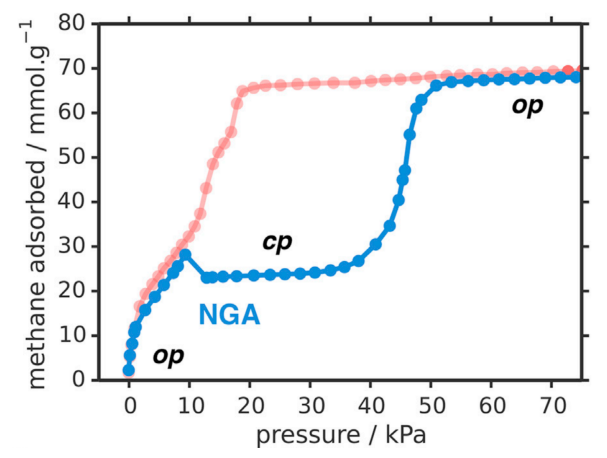

Figure 14: (a) Illustration of the structural transition and phases responsible for NGA in DUT49. (b) The experimental isotherm of DUT-49 during methane adsorption at $111 \mathrm{~K}$ and expected isotherm for a rigid material, calculated by molecular simulation (blue and red, respectively). Reproduced with permission from Ref. [118]. 
a

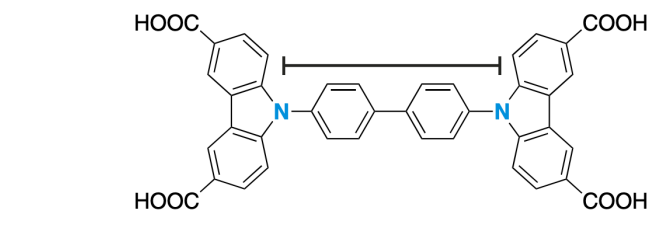

b

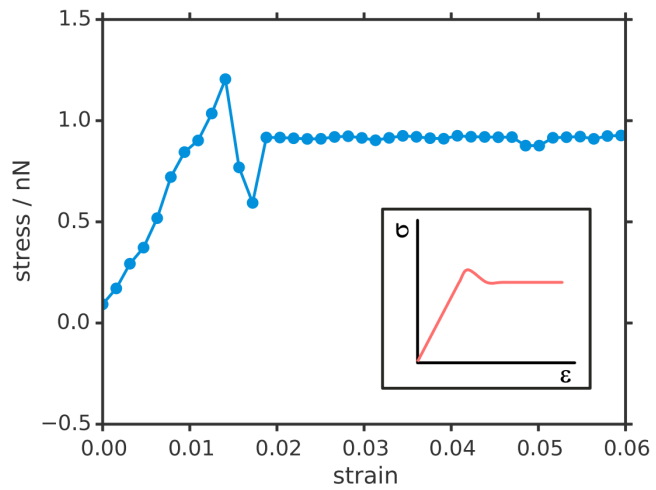

Figure 15: (a) Ligand sub-unit of DUT-49. (b) Stress-strain curve calculated for this ligand with and traditional stress-strain curves for buckling processes displayed onset. Reproduced with permission from Ref. [118]. 


\subsection{Mechanical energy absorption}

Auxetic macroscopic lattice materials have found applications as shock absorbers [9] and similarly MOFs have also been investigated for this application [122]. Nanoscale mechanical systems can be classified depending on the reversibility and hysteresis in the response to mechanical force. This includes shock absorbers, (featuring irreversible compression), dampers (compression-decompression with hysteresis) or molecular springs (compression-decompression without hysteresis). Researchers have combined experiment and simulation to explore the mechanical properties MOFs for use in this context [123].

The wine-rack frameworks MIL-53(Al) and MIL-47(V) have both been investigated for this purpose [122, 124]. These materials are isoreticular and constructed from the same ligands however they differ in metal composition of the metal-oxide one-dimensional chain (aluminium for MIL-53(Al) and vandium for MIL-47(V)). The structure of MIL-47(V) is displayed in Figure 16. MIL-53(Al) requires low hydrostatic pressure of approximately $15 \mathrm{MPa}$ to transform to a closed pore phase and will remain in this phase after the applied pressure is decreased to ambient pressure thus producing a shock absorber-type response. MIL$47(\mathrm{~V})$, however, requires greater applied pressure to transform to a closed pore phase (about $100 \mathrm{MPa}$ ) and will return to the initial open pore phase when pressure is decreased with hysteresis, resulting in a shock dampener behavior displayed in Figure 16 [125].

The force absorbing responses described above can result in the absorption of significant amounts of energy and for reversible processes this can be stored and released. From the pressures and associated volume changes work energies can be derived by $W=\int_{V_{1}}^{V_{2}} P \mathrm{~d} V$. Owing to their large volume changes MOFs are able to store significantly more energy than traditional porous materials such as silicates $\left(11 \mathrm{~J} \mathrm{~g}^{-1}\right)$ [126]. The systems DUT-48 and DUT-49 can absorb 85 and $106 \mathrm{~J} \mathrm{~g}^{-1}$, however, this is irreversible [78].

Recently, this concept of mechanical energy storage was demonstrated beyond bulk measurements by hydrostatic intrustion. Miao et al. reported a study of MOF single crystals under uniaxial compression using in situ transmission electron microscopy [127]. Under high applied pressures, greater than $8 \mathrm{GPa}$, the energy absorption of zirconium MOFs, UiO-66 and UiO-67, reach up to $4 \mathrm{~kJ} \mathrm{~g}^{-1}$. As a comparison the energy released during an explosion of TNT is about $4 \mathrm{~kJ} \mathrm{~g}^{-1}$ [128]. 
a

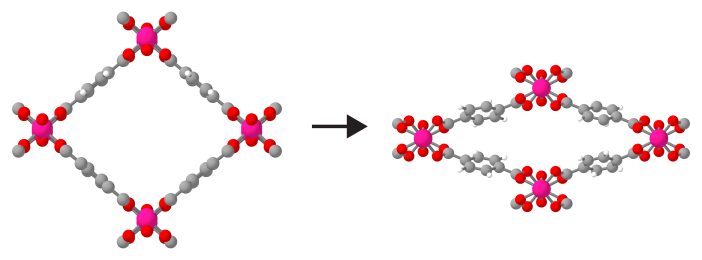

b

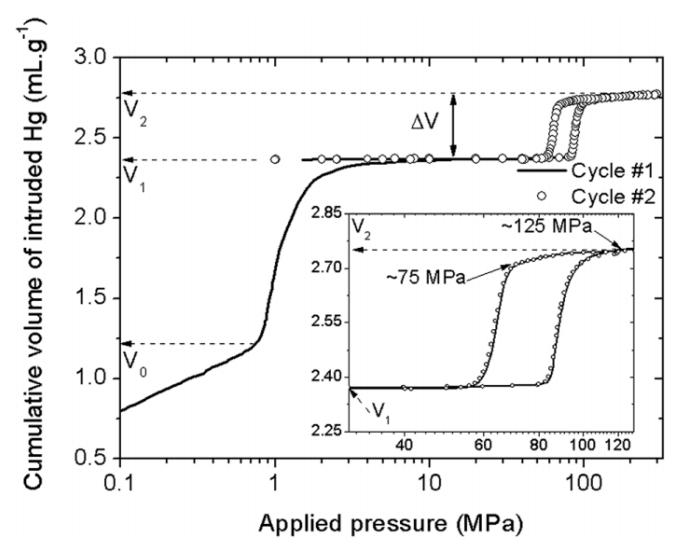

Figure 16: (a) The structural transition exhibited by MIL-47(V), and other wine-rack frameworks. (b) Cumulative volume of intruded mercury for two intrusion/extrusion cycles as a function of the applied pressure as obtained for MIL-47(V). Reproduced with permission from Ref. [125]. 


\subsection{Adsorbents with intrinsic heat management}

The large volume changes that result in impressive mechanical force absorption can also be used in combination with the exceptional adsorption properties of MOFs to provide state-of-the-art gas storage performance.

In 2015, Mason et al. reported the methane storage performance of iron and cobalt MOFs with the ligand 1,4-benzenedipyrazolate (Fe(bdp) and $\mathrm{Co}(\mathrm{bdp})$ ) [129]. These materials display a wine-rack topology, similar to MIL-47(V), and demonstrate a gate-opening process at high pressure (approximately 25 bar for $\mathrm{H}_{2}$ at $77 \mathrm{~K}$ ) [130]. For $\mathrm{CH}_{4}$ at $25^{\circ} \mathrm{C}$, the gate-opening occurs at 16 bar producing the isotherm profile displayed in Figure 17. The stepped isotherm profile provides extraordinary gas uptake and release within a narrow pressure region providing efficient adsorption-desorption cycling. Moreover, the gate-opening process can intrinsically manage the thermal costs associated with storage and release. Exothermic adsorption and endothermic desorption are often neglected when discussing the performance of a material for gas storage. These processes, however, can produce temperature changes of up to $80^{\circ} \mathrm{C}$ resulting in a substantial deterioration of adsorption capacity [131]. Responsive porous materials are able to use the enthalpy change associated with phase transition to offset the cost of adsorption and desorption. Porous materials with weak interactions with $\mathrm{CH}_{4}$ generally display adsorption enthalpies of $-12 \mathrm{~kJ} \mathrm{~mol}^{-1}$ to $-15 \mathrm{~kJ} \mathrm{~mol}^{-1}$ [132], however, for $\mathrm{Co}(\mathrm{bdp})$, the differential enthalpy of adsorption at the steepest part of the $\mathrm{CH}_{4}$ isotherm, where it is likely to be the strongest, is considerably lower at $-8.4 \mathrm{~kJ} \mathrm{~mol}^{-1}$. This decease in the thermal cost of adsorption is due to the endothermic framework expansion partially offsetting the exothermic heat of adsorption.

The remarkable gas storage performance of $\mathrm{Fe}(\mathrm{bdp})$ and $\mathrm{Co}(\mathrm{bdp})$ has inspired researchers to consider other materials which display gate-opening pressures for this purpose. Hiraide et al. investigated the ELM-11 system for the capture and storage of $\mathrm{CO}_{2}$ using molecular simulation [133]. They observed that the flexible ELM-11 structure can produce a thermal offset, at $298 \mathrm{~K}$, of over $41 \%$ and also indicate that intrinsic thermal management is also effective for desorption. Furthermore, ELM-11 displays two steps in the isotherm thus it appears systems which exhibit multiple gate-opening steps are also promising candidates for intrinsic heat management adsorbents. The previously discussed ZIF-7 analogs reported by McGuirk et al. were also investigated for this purpose and the heat released from $\mathrm{CH}_{4}$ adsorption at in ZIF-7 and ZIF-9 was observed to be offset by between 18 and $20 \%$ [108]. 
a

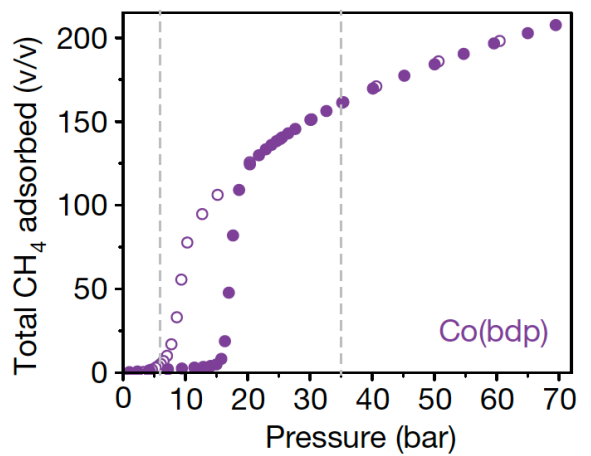

b

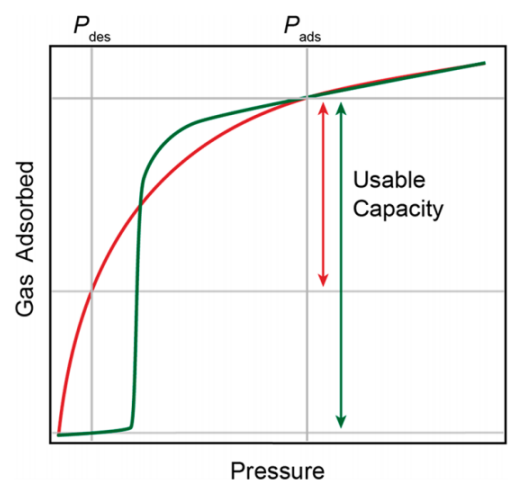

Figure 17: (a) $\mathrm{CH}_{4}$ adsorption isotherm for $\mathrm{Co}(\mathrm{bdp})$ at $25^{\circ} \mathrm{C}$. (b) Expected adsorption behavior for a traditional microporous material (red) and stepped adsorption material (green). Materials with stepped adsorption profiles have greater usable capacities than traditional porous materials for a pressure swing process (between $P_{\text {ads }}$ and $P_{\text {des }}$ ) as indicated by the arrows. Reproduced with permission from Refs. 129 and 108 .

The above highlight only a few of the possible applications of meta-MOFs and related materials. The unique behavior exhibited by these materials provide boundless opportunity. This is especially true for materials that display changes in phase upon the application of stimuli, which show promise for the development of novel switches.

\section{Summary and perspectives}

Throughout this review we have described many notable examples from materials that display unusual mechanical, thermal, and adsorption-driven phenomena. These include properties such as negative compressibility, complete auxetic- 
ity, negative thermal expansion, gate opening and negative gas adsorption. If one were to look back at the process of discovery of these novel and exotic behaviors in framework materials, one would find that it was in all cases a product of chance. Though there has been a large body of work on the understanding of the microscopic roots of the phenomena, and similarly a significant effort spent on tuning and modification of this behavior, the process of identification of novel meta-MOFs is still wide open. Finding these needles in the haystack, which is the ever growing number of known MOF materials, is an enormous challenge.

Observations show that many of the materials we classify as meta-MOFs share common traits in ligand composition or topology, which provide some guidance to the design of targeted "unusual" responses. Many MOFs which share similar structural features, however, are not reported to exhibit the same bizarre properties. One possible reason behind that fact, often overlooked, is the realization that crystal size has a significant influence on flexibility [134, 135]. Moreover, kinetics of the structural transitions can also affect the response of these materials, with the presence of spatial transient state [136]. Finally, the presence of defects in the crystalline structure - and the possibility of disorder - can strongly affect the material's response as well [137]. Nevertheless, these effects of crystal size, kinetics, defects and disorder are currently not well understood and may represent a barrier to the discovery of novel responsive materials and anomalous properties. Yet, they could also provide a unique approach to tuning a material's response.

Going beyond this view from the "eye of the chemist" is necessary to generate more systematic approach to discovery. For more conventional properties, largescale computational screening of databases of real and hypothetical materials have shown to be useful tools, e.g., for the selection of inorganic materials with potential for water splitting applications [138], or porous materials with high capacity for specific gases [139]. For meta-MOFs, no large-scale screening study has been published so far - however, it is clear from the examples above that computer simulations, in combination with experimental characterization techniques, play a vital role in the our understanding. Current progress towards multiscale modeling will provide unparalleled understanding of these complex systems on a wide range of length and timescales [140], and thus be applicable to the design of novel materials or large-scale screening of novel properties for known materials.

\section{Acknowledgments}

We thank Marc-André Delsuc for the gift of the Hoberman Twist-O sphere displayed in Figure 7 


\section{References}

\section{References}

[1] M. Kadic, T. Bückmann, R. Schittny, M. Wegener, Metamaterials beyond electromagnetism, Rep. Prog. Phys. 76 (2013) 126501.

[2] K. Bertoldi, V. Vitelli, J. Christensen, M. van Hecke, Flexible mechanical metamaterials, Nat. Rev. Mater. 2 (2017) 17066.

[3] D. R. Smith, Metamaterials and negative refractive index, Science 305 (2004) 788-792.

[4] Y. Ding, Z. Liu, C. Qiu, J. Shi, Metamaterial with simultaneously negative bulk modulus and mass density, Phys. Rev. Lett. 99 (2007) 093904.

[5] V. M. Shalaev, PHYSICS: Transforming light, Science 322 (2008) 384386.

[6] J. K. Rowling, The Tale of the Three Brothers, in: The Tales of Beedle the Bard, Bloomsbury Publishing Plc, 2008.

[7] T. Bückmann, M. Thiel, M. Kadic, R. Schittny, M. Wegener, An elastomechanical unfeelability cloak made of pentamode metamaterials, Nat. Commun. 5 (2014) 4130.

[8] V. M. Shalaev, Optical negative-index metamaterials, Nat. Photonics 1 (2007) 41-48.

[9] G. N. Greaves, A. L. Greer, R. S. Lakes, T. Rouxel, Poisson's ratio and modern materials, Nat. Mater. 10 (2011) 823-837.

[10] D. Schurig, J. J. Mock, B. J. Justice, S. A. Cummer, J. B. Pendry, A. F. Starr, D. R. Smith, Metamaterial electromagnetic cloak at microwave frequencies, Science 314 (2006) 977-980.

[11] C. M. Soukoulis, M. Wegener, Past achievements and future challenges in the development of three-dimensional photonic metamaterials, Nat. Photonics 5 (2011) 523-530.

[12] M. Kadic, T. Bückmann, N. Stenger, M. Thiel, M. Wegener, On the practicability of pentamode mechanical metamaterials, Appl. Phys. Lett. 100 (2012) 191901. 
[13] G. W. Milton, A. V. Cherkaev, Which elasticity tensors are realizable?, J. Eng. Mater. Technol. 117 (1995) 483.

[14] F.-X. Coudert, Responsive metal-organic frameworks and framework materials: Under pressure, taking the heat, in the spotlight with friends, Chem. Mater. 27 (2015) 1905-1916.

[15] Q. Wang, J. A. Jackson, Q. Ge, J. B. Hopkins, C. M. Spadaccini, N. X. Fang, Lightweight mechanical metamaterials with tunable negative thermal expansion, Phys. Rev. Lett. 117 (2016) 175901.

[16] J. D. Evans, G. Fraux, R. Gaillac, D. Kohen, F. Trousselet, J.-M. Vanson, F.$\mathrm{X}$. Coudert, Computational chemistry methods for nanoporous materials, Chem. Mater. 29 (2016) 199-212.

[17] J. N. Grima, V. Zammit, R. Gatt, Negative thermal expansion, Xjenza 11 (2006) 17-29.

[18] G. D. Barrera, J. A. O. Bruno, T. H. K. Barron, N. L. Allan, Negative thermal expansion, J. Phys. Condens. Matter 17 (2005) R217-R252.

[19] W. Miller, C. W. Smith, D. S. Mackenzie, K. E. Evans, Negative thermal expansion: a review, J. Mater. Sci. 44 (2009) 5441-5451.

[20] T. A. Mary, J. S. O. Evans, T. Vogt, A. W. Sleight, Negative thermal expansion from 0.3 to 1050 Kelvin in $\mathrm{ZrW}_{2} \mathrm{O}_{8}$, Science 272 (1996) 90-92.

[21] A. Versluis, W. H. Douglas, R. L. Sakaguchi, Thermal expansion coefficient of dental composites measured with strain gauges, Dental Materials 12 (1996) 290-294.

[22] M. P. Attfield, A. W. Sleight, Exceptional negative thermal expansion in $\mathrm{AlPO}_{4}-17$, Chem. Mater. 10 (1998) 2013-2019.

[23] M. P. Attfield, Strong negative thermal expansion in siliceous faujasite, Chem. Commun. (1998) 601-602.

[24] D. A. Woodcock, P. Lightfoot, L. A. Villaescusa, M.-J. Díaz-Cabañas, M. A. Camblor, D. Engberg, Negative thermal expansion in the siliceous zeolites chabazite and ITQ-4: A neutron powder diffraction study, Chem. Mater. 11 (1999) 2508-2514. 
[25] D. A. Woodcock, P. Lightfoot, P. A. Wright, L. A. Villaescusa, M. A. Camblor, Strong negative thermal expansion in the siliceous zeolites ITQ-1, ITQ-3 and SSZ-23, J. Mater. Chem. 9 (1999) 349-351.

[26] P. Lightfoot, D. A. Woodcock, M. J. Maple, L. A. Villaescusa, P. A. Wright, The widespread occurrence of negative thermal expansion in zeolites, J. Mater. Chem. 11 (2001) 212-216.

[27] B. Marinkovic, P. Jardim, A. Saavedra, L. Lau, C. Baehtz, R. de Avillez, F. Rizzo, Negative thermal expansion in hydrated HZSM-5 orthorhombic zeolite, Microporous and Mesoporous Mater. 71 (2004) 117-124.

[28] P. Tschaufeser, S. C. Parker, Thermal expansion behavior of zeolites and $\mathrm{AlPO}_{4}$ s, J. Phys. Chem. 99 (1995) 10609-10615.

[29] D. Dubbeldam, K. Walton, D. Ellis, R. Snurr, Exceptional negative thermal expansion in isoreticular metal-organic frameworks, Angew. Chem. Int. Ed. 46 (2007) 4496-4499.

[30] S. S. Han, W. A. Goddard, Metal-organic frameworks provide large negative thermal expansion behavior, J. Phys. Chem. C 111 (2007) 1518515191.

[31] W. Zhou, H. Wu, T. Yildirim, J. R. Simpson, A. R. H. Walker, Origin of the exceptional negative thermal expansion in metal-organic framework-5 $\mathrm{Zn}_{4} \mathrm{O}$ (1,4-benzenedicarboxylate) $)_{3}$, Phys. Rev. B 78 (2008) 2300.

[32] Y. Wu, A. Kobayashi, G. Halder, V. Peterson, K. Chapman, N. Lock, P. Southon, C. Kepert, Negative thermal expansion in the metal-organic framework material $\mathrm{Cu}_{3}(1,3,5 \text {-benzenetricarboxylate })_{2}$, Angew. Chem. Int. Ed. 47 (2008) 8929-8932.

[33] S. Henke, A. Schneemann, R. A. Fischer, Massive anisotropic thermal expansion and thermo-responsive breathing in metal-organic frameworks modulated by linker functionalization, Adv. Funct. Mater. 23 (2013) 59905996.

[34] W. L. Queen, C. M. Brown, D. K. Britt, P. Zajdel, M. R. Hudson, O. M. Yaghi, Site-specific $\mathrm{CO}_{2}$ adsorption and zero thermal expansion in an anisotropic pore network, J. Phys. Chem. C 115 (2011) 24915-24919. 
[35] L. Zhao, C. Zhong, Negative thermal expansion in covalent organic framework COF-102, J. Phys. Chem. C 113 (2009) 16860-16862.

[36] L. D. DeVries, P. M. Barron, E. P. Hurley, C. Hu, W. Choe, "Nanoscale lattice fence" in a metal-organic framework: Interplay between hinged topology and highly anisotropic thermal response, J. Am. Chem. Soc. 133 (2011) 14848-14851.

[37] N. Lock, Y. Wu, M. Christensen, L. J. Cameron, V. K. Peterson, A. J. Bridgeman, C. J. Kepert, B. B. Iversen, Elucidating negative thermal expansion in MOF-5, J. Phys. Chem. C 114 (2010) 16181-16186.

[38] I. E. Collings, M. G. Tucker, D. A. Keen, A. L. Goodwin, Geometric switching of linear to area negative thermal expansion in uniaxial metalorganic frameworks, CrystEngComm 16 (2014) 3498-3506.

[39] A. L. Goodwin, B. J. Kennedy, C. J. Kepert, Thermal expansion matching via framework flexibility in zinc dicyanometallates, J. Am. Chem. Soc. 131 (2009) 6334-6335.

[40] I. Grobler, V. J. Smith, P. M. Bhatt, S. A. Herbert, L. J. Barbour, Tunable anisotropic thermal expansion of a porous zinc(II) metal-organic framework, J. Am. Chem. Soc. 135 (2013) 6411-6414.

[41] L. Bouëssel du Bourg, A. U. Ortiz, A. Boutin, F.-X. Coudert, Thermal and mechanical stability of zeolitic imidazolate frameworks polymorphs, APL Materials 2 (2014) 124110.

[42] K. S. Park, Z. Ni, A. P. Cote, J. Y. Choi, R. Huang, F. J. Uribe-Romo, H. K. Chae, M. O'Keeffe, O. M. Yaghi, Exceptional chemical and thermal stability of zeolitic imidazolate frameworks, Proc. Nat. Acad. Sci. 103 (2006) 10186-10191.

[43] M. J. Cliffe, J. A. Hill, C. A. Murray, F.-X. Coudert, A. L. Goodwin, Defectdependent colossal negative thermal expansion in UiO-66(Hf) metalorganic framework, Phys. Chem. Chem. Phys. 17 (2015) 11586-11592.

[44] A. B. Cairns, A. L. Goodwin, Negative linear compressibility, Phys. Chem. Chem. Phys. 17 (2015) 20449-20465. 
[45] S. A. Hodgson, J. Adamson, S. J. Hunt, M. J. Cliffe, A. B. Cairns, A. L. Thompson, M. G. Tucker, N. P. Funnell, A. L. Goodwin, Negative area compressibility in silver(I) tricyanomethanide, Chem. Commun. 50 (2014) 5264-5266.

[46] W. Cai, A. Gładysiak, M. Anioła, V. J. Smith, L. J. Barbour, A. Katrusiak, Giant negative area compressibility tunable in a soft porous framework material, J. Am. Chem. Soc. 137 (2015) 9296-9301.

[47] P. Serra-Crespo, A. Dikhtiarenko, E. Stavitski, J. Juan-Alcañiz, F. Kapteijn, F.-X. Coudert, J. Gascon, Experimental evidence of negative linear compressibility in the MIL-53 metal-organic framework family, CrystEngComm 17 (2015) 276-280.

[48] W. Li, M. R. Probert, M. Kosa, T. D. Bennett, A. Thirumurugan, R. P. Burwood, M. Parinello, J. A. K. Howard, A. K. Cheetham, Negative linear compressibility of a metal-organic framework, J. Am. Chem. Soc. 134 (2012) 11940-11943.

[49] A. B. Cairns, J. Catafesta, C. Levelut, J. Rouquette, A. van der Lee, L. Peters, A. L. Thompson, V. Dmitriev, J. Haines, A. L. Goodwin, Giant negative linear compressibility in zinc dicyanoaurate, Nature Mater. 12 (2013) 212-216.

[50] J. M. Ogborn, I. E. Collings, S. A. Moggach, A. L. Thompson, A. L. Goodwin, Supramolecular mechanics in a metal-organic framework, Chem. Sci. 3 (2012) 3011.

[51] W. Cai, A. Katrusiak, Giant negative linear compression positively coupled to massive thermal expansion in a metal-organic framework, Nature Commun. 5 (2014) 1522.

[52] A. U. Ortiz, A. Boutin, A. H. Fuchs, F.-X. Coudert, Anisotropic elastic properties of flexible metal-organic frameworks: How soft are soft porous crystals?, Phys. Rev. Lett. 109 (2012).

[53] S. Sun, S. Henke, M. T. Wharmby, H. H.-M. Yeung, W. Li, A. K. Cheetham, Mechanical properties of a calcium dietary supplement, calcium fumarate trihydrate, Inorg. Chem. 54 (2015) 11186-11192. 
[54] G. Feng, W.-X. Zhang, L. Dong, W. Li, W. Cai, W. Wei, L. Ji, Z. Lin, P. Lu, Negative area compressibility of a hydrogen-bonded two-dimensional material, Chem. Sci. (2019) 1522.

[55] A. Marmier, Z. A. Lethbridge, R. I. Walton, C. W. Smith, S. C. Parker, K. E. Evans, ElAM: A computer program for the analysis and representation of anisotropic elastic properties, Comput. Phys. Commun. 181 (2010) 21022115.

[56] S. C. McKellar, S. A. Moggach, Structural studies of metal-organic frameworks under high pressure, Acta Cryst. B 71 (2015) 587-607.

[57] G. Ortiz, H. Nouali, C. Marichal, G. Chaplais, J. Patarin, Energetic performances of the metal-organic framework ZIF-8 obtained using high pressure water intrusion-extrusion experiments, Phys. Chem. Chem. Phys. 15 (2013) 4888.

[58] G. Ortiz, H. Nouali, C. Marichal, G. Chaplais, J. Patarin, Versatile energetic behavior of ZIF-8 upon high pressure intrusion-extrusion of aqueous electrolyte solutions, J. Phys. Chem. C 118 (2014) 7321-7328.

[59] G. Fraux, F.-X. Coudert, A. Boutin, A. H. Fuchs, Forced intrusion of water and aqueous solutions in microporous materials: from fundamental thermodynamics to energy storage devices, Chem. Soc. Rev. 46 (2017) 74217437.

[60] E. C. Spencer, R. J. Angel, N. L. Ross, B. E. Hanson, J. A. K. Howard, Pressure-induced cooperative bond rearrangement in a zinc imidazolate framework: A high-pressure single-crystal X-ray diffraction study, J. Am. Chem. Soc. 131 (2009) 4022-4026.

[61] K. J. Gagnon, C. M. Beavers, A. Clearfield, MOFs under pressure: The reversible compression of a single crystal, J. Am. Chem. Soc. 135 (2013) $1252-1255$.

[62] A. U. Ortiz, A. Boutin, K. J. Gagnon, A. Clearfield, F.-X. Coudert, Remarkable pressure responses of metal-organic frameworks: Proton transfer and linker coiling in zinc alkyl gates, J. Am. Chem. Soc. 136 (2014) 1154011545 . 
[63] S. H. Lapidus, G. J. Halder, P. J. Chupas, K. W. Chapman, Exploiting high pressures to generate porosity, polymorphism, and lattice expansion in the nonporous molecular framework $\mathrm{Zn}(\mathrm{CN})_{2}$, J. Am. Chem. Soc. 135 (2013) 7621-7628.

[64] E. C. Spencer, M. S. R. N. Kiran, W. Li, U. Ramamurty, N. L. Ross, A. K. Cheetham, Pressure-induced bond rearrangement and reversible phase transformation in a metal-organic framework, Angew. Chem. Int. Ed. 53 (2014) 5583-5586.

[65] K. E. Evans, A. Alderson, Auxetic materials: Functional materials and structures from lateral thinking!, Adv. Mater. 12 (2000) 617-628.

[66] T. Hughes, A. Marmier, K. Evans, Auxetic frameworks inspired by cubic crystals, Int. J. Solids Struct. 47 (2010) 1469-1476.

[67] Z. A. Lethbridge, R. I. Walton, A. S. Marmier, C. W. Smith, K. E. Evans, Elastic anisotropy and extreme Poisson's ratios in single crystals, Acta Materialia 58 (2010) 6444-6451.

[68] J. Dagdelen, J. Montoya, M. de Jong, K. Persson, Computational prediction of new auxetic materials, Nature Commun. 8 (2017) 124.

[69] J. N. Grima, R. Jackson, A. Alderson, K. E. Evans, Do zeolites have negative Poisson's ratios?, Adv. Mater. 12 (2000) 1912-1918.

[70] J. N. Grima, R. Gatt, V. Zammit, J. J. Williams, K. E. Evans, A. Alderson, R. I. Walton, Natrolite: A zeolite with negative Poisson's ratios, J. Appl. Phys. 101 (2007) 086102.

[71] M. R. Ryder, B. Civalleri, J.-C. Tan, Isoreticular zirconium-based metalorganic frameworks: discovering mechanical trends and elastic anomalies controlling chemical structure stability, Phys. Chem. Chem. Phys. 18 (2016) 9079-9087.

[72] M. R. Ryder, J.-C. Tan, Explaining the mechanical mechanisms of zeolitic metal-organic frameworks: revealing auxeticity and anomalous elasticity, Dalton Trans. 45 (2016) 4154-4161.

[73] J.-C. Tan, B. Civalleri, A. Erba, E. Albanese, Quantum mechanical predictions to elucidate the anisotropic elastic properties of zeolitic imidazolate frameworks: ZIF-4 vs. ZIF-zni, CrystEngComm 17 (2015) 375-382. 
[74] J. Shim, C. Perdigou, E. R. Chen, K. Bertoldi, P. M. Reis, Buckling-induced encapsulation of structured elastic shells under pressure, Proc. Nat. Acad. Sci. 109 (2012) 5978-5983.

[75] M. Siddorn, F.-X. Coudert, K. E. Evans, A. Marmier, A systematic typology for negative Poisson's ratio materials and the prediction of complete auxeticity in pure silica zeolite JST, Phys. Chem. Chem. Phys. 17 (2015) 17927-17933.

[76] G. Y. Gor, P. Huber, N. Bernstein, Adsorption-induced deformation of nanoporous materials—a review, Appl. Phys. Rev. 4 (2017) 011303.

[77] I. Beurroies, M. Boulhout, P. L. Llewellyn, B. Kuchta, G. Férey, C. Serre, R. Denoyel, Using pressure to provoke the structural transition of metalorganic frameworks, Angew. Chem. Int. Ed. 49 (2010) 7526-7529.

[78] S. Krause, J. D. Evans, V. Bon, I. Senkovska, S. Ehrling, U. Stoeck, P. G. Yot, P. Iacomi, P. Llewellyn, G. Maurin, F.-X. Coudert, S. Kaskel, Adsorption contraction mechanics: Understanding breathing energetics in isoreticular metal-organic frameworks, J. Phys. Chem. C 122 (2018) 1917119179.

[79] T. Loiseau, C. Serre, C. Huguenard, G. Fink, F. Taulelle, M. Henry, T. Bataille, G. Férey, A rationale for the large breathing of the porous aluminum terephthalate (MIL-53) upon hydration, Chem. Eur. J. 10 (2004) 1373-1382.

[80] C. M. Simon, E. Braun, C. Carraro, B. Smit, Statistical mechanical model of gas adsorption in porous crystals with dynamic moieties, Proc. Nat. Acad. Sci. 114 (2017) E287-E296.

[81] G. Y. Gor, A. V. Neimark, Adsorption-induced deformation of mesoporous solids, Langmuir 26 (2010) 13021-13027.

[82] P. I. Ravikovitch, A. V. Neimark, Density functional theory model of adsorption deformation, Langmuir 22 (2006) 10864-10868.

[83] S. Horike, S. Shimomura, S. Kitagawa, Soft porous crystals, Nature Chem. 1 (2009) 695-704. 
[84] Y. Long, J. C. Palmer, B. Coasne, M. Śliwinska Bartkowiak, K. E. Gubbins, Pressure enhancement in carbon nanopores: a major confinement effect, Phys. Chem. Chem. Phys. 13 (2011) 17163.

[85] J.-C. Tan, B. Civalleri, C.-C. Lin, L. Valenzano, R. Galvelis, P.-F. Chen, T. D. Bennett, C. Mellot-Draznieks, C. M. Zicovich-Wilson, A. K. Cheetham, Exceptionally low shear modulus in a prototypical imidazolebased metal-organic framework, Phys. Rev. Lett. 108 (2012).

[86] F. Mouhat, D. Bousquet, A. Boutin, L. Bouëssel du Bourg, F.-X. Coudert, A. H. Fuchs, Softening upon adsorption in microporous materials: A counterintuitive mechanical response, J. Phys. Chem. Lett. 6 (2015) 4265-4269.

[87] K. W. Chapman, G. J. Halder, P. J. Chupas, Pressure-induced amorphization and porosity modification in a metal-organic framework, J. Am. Chem. Soc. 131 (2009) 17546-17547.

[88] T. D. Bennett, P. Simoncic, S. A. Moggach, F. Gozzo, P. Macchi, D. A. Keen, J.-C. Tan, A. K. Cheetham, Reversible pressure-induced amorphization of a zeolitic imidazolate framework (ZIF-4), Chem. Commun. 47 (2011) 7983.

[89] J. D. Evans, F.-X. Coudert, Microscopic mechanism of chiral induction in a metal-organic framework, J. Am. Chem. Soc. 138 (2016) 6131-6134.

[90] S.-Y. Zhang, D. Li, D. Guo, H. Zhang, W. Shi, P. Cheng, L. Wojtas, M. J. Zaworotko, Synthesis of a chiral crystal form of MOF-5, CMOF-5, by chiral induction, J. Am. Chem. Soc. 137 (2015) 15406-15409.

[91] M. Baise, P. M. Maffettone, F. Trousselet, N. P. Funnell, F.-X. Coudert, A. L. Goodwin, Negative hydration expansion in $\mathrm{ZrW}_{2} \mathrm{O}_{8}$ : Microscopic mechanism, spaghetti dynamics, and negative thermal expansion, Phys. Rev. Lett. 120 (2018).

[92] F. T. Meehan, The expansion of charcoal on sorption of carbon dioxide, Proc. Royal Soc. A 115 (1927) 199-207.

[93] R. Kitaura, K. Seki, G. Akiyama, S. Kitagawa, Porous coordinationpolymer crystals with gated channels specific for supercritical gases, Angew. Chem. Int. Ed. 42 (2003) 428-431. 
[94] D. Li, K. Kaneko, Hydrogen bond-regulated microporous nature of copper complex-assembled microcrystals, Chem. Phys. Lett. 335 (2001) 50-56.

[95] A. Kondo, N. Kojima, H. Kajiro, H. Noguchi, Y. Hattori, F. Okino, K. Maeda, T. Ohba, K. Kaneko, H. Kanoh, Gas adsorption mechanism and kinetics of an elastic layer-structured metal-organic framework, J. Phys. Chem. C 116 (2012) 4157-4162.

[96] H. Tanaka, S. Hiraide, A. Kondo, M. T. Miyahara, Modeling and visualization of $\mathrm{CO}_{2}$ adsorption on elastic layer-structured metal-organic framework-11: Toward a better understanding of gate adsorption behavior, J. Phys. Chem. C 119 (2015) 11533-11543.

[97] A. Kultaeva, V. Bon, M. S. Weiss, A. Pöppl, S. Kaskel, Elucidating the formation and transformation mechanisms of the switchable metal-organic framework ELM-11 by powder and single-crystal EPR study, Inorg. Chem. 57 (2018) 11920-11929.

[98] N. Klein, C. Herzog, M. Sabo, I. Senkovska, J. Getzschmann, S. Paasch, M. R. Lohe, E. Brunner, S. Kaskel, Monitoring adsorption-induced switching by ${ }^{129} \mathrm{Xe}$ NMR spectroscopy in a new metal-organic framework $\mathrm{Ni}_{2}$ (2,6-ndc) $)_{2}$ (dabco), Phys. Chem. Chem. Phys. 12 (2010) 11778.

[99] V. Bon, N. Klein, I. Senkovska, A. Heerwig, J. Getzschmann, D. Wallacher, I. Zizak, M. Brzhezinskaya, U. Mueller, S. Kaskel, Exceptional adsorptioninduced cluster and network deformation in the flexible metal-organic framework DUT-8(Ni) observed by in situ X-ray diffraction and EXAFS, Phys. Chem. Chem. Phys. 17 (2015) 17471-17479.

[100] D. Fairen-Jimenez, S. A. Moggach, M. T. Wharmby, P. A. Wright, S. Parsons, T. Düren, Opening the gate: Framework flexibility in ZIF-8 explored by experiments and simulations, J. Am. Chem. Soc. 133 (2011) 8900-8902.

[101] C. L. Hobday, C. H. Woodall, M. J. Lennox, M. Frost, K. Kamenev, T. Düren, C. A. Morrison, S. A. Moggach, Understanding the adsorption process in ZIF-8 using high pressure crystallography and computational modelling, Nature Commun. 9 (2018).

[102] G. Chaplais, G. Fraux, J.-L. Paillaud, C. Marichal, H. Nouali, A. H. Fuchs, F.-X. Coudert, J. Patarin, Impacts of the imidazolate linker substitution 
$\left(\mathrm{CH}_{3}, \mathrm{Cl}\right.$, or $\left.\mathrm{Br}\right)$ on the structural and adsorptive properties of ZIF-8, J. Phys. Chem. C 122 (2018) 26945-26955.

[103] F.-X. Coudert, Molecular mechanism of swing effect in zeolitic imidazolate framework ZIF-8: Continuous deformation upon adsorption, ChemPhysChem 18 (2017) 2732-2738.

[104] C. O. Ania, E. García-Pérez, M. Haro, J. J. Gutiérrez-Sevillano, T. ValdésSolís, J. B. Parra, S. Calero, Understanding gas-induced structural deformation of ZIF-8, J. Phys. Chem. Lett. 3 (2012) 1159-1164.

[105] S. Henke, A. Schneemann, A. Wütscher, R. A. Fischer, Directing the breathing behavior of pillared-layered metal-organic frameworks via a systematic library of functionalized linkers bearing flexible substituents, J. Am. Chem. Soc. 134 (2012) 9464-9474.

[106] N. Klein, H. C. Hoffmann, A. Cadiau, J. Getzschmann, M. R. Lohe, S. Paasch, T. Heydenreich, K. Adil, I. Senkovska, E. Brunner, S. Kaskel, Structural flexibility and intrinsic dynamics in the $\mathrm{M}_{2}(2,6-n d c){ }_{2}$ (dabco) (M $=\mathrm{Ni}, \mathrm{Cu}, \mathrm{Co}, \mathrm{Zn}$ ) metal-organic frameworks, J. Mater. Chem. 22 (2012) 10303.

[107] A. Schneemann, P. Vervoorts, I. Hante, M. Tu, S. Wannapaiboon, C. Sternemann, M. Paulus, D. F. Wieland, S. Henke, R. A. Fischer, Different breathing mechanisms in flexible pillared-layered metal-organic frameworks: Impact of the metal center, Chem. Mater. 30 (2018) 1667-1676.

[108] C. M. McGuirk, T. Runčevski, J. Oktawiec, A. Turkiewicz, M. K. Taylor, J. R. Long, Influence of metal substitution on the pressure-induced phase change in flexible zeolitic imidazolate frameworks, J. Am. Chem. Soc. 140 (2018) 15924-15933.

[109] A. U. Ortiz, M.-A. Springuel-Huet, F.-X. Coudert, A. H. Fuchs, A. Boutin, Predicting mixture coadsorption in soft porous crystals: Experimental and theoretical study of $\mathrm{CO}_{2} / \mathrm{CH}_{4}$ in MIL-53(Al), Langmuir 28 (2011) 494498.

[110] D. Tanaka, K. Nakagawa, M. Higuchi, S. Horike, Y. Kubota, T. C. Kobayashi, M. Takata, S. Kitagawa, Kinetic gate-opening process in a flexible porous coordination polymer, Angew. Chem. Int. Ed. 47 (2008) 3914-3918. 
[111] X. Li, X. Chen, F. Jiang, L. Chen, S. Lu, Q. Chen, M. Wu, D. Yuan, $\mathrm{M}$. Hong, The dynamic response of a flexible indium based metal-organic framework to gas sorption, Chem. Commun. 52 (2016) 2277-2280.

[112] J. Su, S. Yuan, H.-Y. Wang, L. Huang, J.-Y. Ge, E. Joseph, J. Qin, T. Cagin, J.-L. Zuo, H.-C. Zhou, Redox-switchable breathing behavior in tetrathiafulvalene-based metal-organic frameworks, Nature Commun. 8 (2017).

[113] Y.-X. Shi, W.-X. Li, W.-H. Zhang, J.-P. Lang, Guest-induced switchable breathing behavior in a flexible metal-organic framework with pronounced negative gas pressure, Inorg. Chem. 57 (2018) 8627-8633.

[114] S. Krause, V. Bon, I. Senkovska, U. Stoeck, D. Wallacher, D. M. Többens, S. Zander, R. S. Pillai, G. Maurin, F.-X. Coudert, S. Kaskel, A pressureamplifying framework material with negative gas adsorption transitions, Nature 532 (2016) 348-352.

[115] L. Riekert, Instability of sorption complexes in synthetic faujasites, J. Phys. Chem. 73 (1969) 4384-4386.

[116] J. V. Smith, Crystal structures with a chabazite framework. part v. interpretation of physicochemical properties in terms of the crystal structure, J. Chem. Soc. (1964) 3759-3770.

[117] U. Stoeck, S. Krause, V. Bon, I. Senkovska, S. Kaskel, A highly porous metal-organic framework, constructed from a cuboctahedral supermolecular buildinangew. chem. int. ed.g block, with exceptionally high methane uptake, Chem. Commun. 48 (2012) 10841.

[118] J. D. Evans, L. Bocquet, F.-X. Coudert, Origins of negative gas adsorption, Chem 1 (2016) 873-886.

[119] X. Ren, J. Shen, P. Tran, T. D. Ngo, Y. M. Xie, Design and characterisation of a tuneable 3D buckling-induced auxetic metamaterial, Materials \& Design 139 (2018) 336-342.

[120] N. C. Burtch, J. Heinen, T. D. Bennett, D. Dubbeldam, M. D. Allendorf, Mechanical properties in metal-organic frameworks: Emerging opportunities and challenges for device functionality and technological applications, Adv. Mater. 30 (2017) 1704124. 
[121] Z. Zhai, Y. Wang, H. Jiang, Origami-inspired, on-demand deployable and collapsible mechanical metamaterials with tunable stiffness, Proc. Nat. Acad. Sci. 115 (2018) 2032-2037.

[122] P. G. Yot, Z. Boudene, J. Macia, D. Granier, L. Vanduyfhuys, T. Verstraelen, V. V. Speybroeck, T. Devic, C. Serre, G. Férey, N. Stock, G. Maurin, Metal-organic frameworks as potential shock absorbers: the case of the highly flexible MIL-53(Al), Chem. Commun. 50 (2014) 9462-9464.

[123] S. M. J. Rogge, M. Waroquier, V. V. Speybroeck, Reliably modeling the mechanical stability of rigid and flexible metal-organic frameworks, Acc. Chem. Res. 51 (2017) 138-148.

[124] J. Wieme, L. Vanduyfhuys, S. M. J. Rogge, M. Waroquier, V. V. Speybroeck, Exploring the flexibility of MIL-47(V)-type materials using force field molecular dynamics simulations, J. Phys. Chem. C 120 (2016) 1493414947.

[125] P. G. Yot, Q. Ma, J. Haines, Q. Yang, A. Ghoufi, T. Devic, C. Serre, V. Dmitriev, G. Férey, C. Zhong, G. Maurin, Large breathing of the MOF MIL-47 $\left(\mathrm{V}^{\mathrm{IV}}\right)$ under mechanical pressure: a joint experimental-modelling exploration, Chem. Sci. 3 (2012) 1100.

[126] L. Tzanis, H. Nouali, T. J. Daou, M. Soulard, J. Patarin, Influence of the aqueous medium on the energetic performances of silicalite-1, Mater. Lett. 115 (2014) 229-232.

[127] Y.-R. Miao, Z. Su, K. S. Suslick, Energy storage during compression of metal-organic frameworks, J. Am. Chem. Soc. 139 (2017) 4667-4670.

[128] I. Sochet, Blast effects of external explosions, in: Eighth International Symposium on Hazards, Prevention, and Mitigation of Industrial Explosions.

[129] J. A. Mason, J. Oktawiec, M. K. Taylor, M. R. Hudson, J. Rodriguez, J. E. Bachman, M. I. Gonzalez, A. Cervellino, A. Guagliardi, C. M. Brown, P. L. Llewellyn, N. Masciocchi, J. R. Long, Methane storage in flexible metalorganic frameworks with intrinsic thermal management, Nature 527 (2015) $357-361$. 
[130] H. J. Choi, M. Dincă, J. R. Long, Broadly hysteretic $\mathrm{H}_{2}$ adsorption in the microporous metal-organic framework $\mathrm{Co}(1,4$-benzenedipyrazolate), J. Am. Chem. Soc. 130 (2008) 7848-7850.

[131] K. S. Walton, M. D. LeVan, Natural gas storage cycles: Influence of nonisothermal effects and heavy alkanes, Adsorption 12 (2006) 227-235.

[132] J. A. Mason, M. Veenstra, J. R. Long, Evaluating metal-organic frameworks for natural gas storage, Chem. Sci. 5 (2014) 32-51.

[133] S. Hiraide, H. Tanaka, N. Ishikawa, M. T. Miyahara, Intrinsic thermal management capabilities of flexible metal-organic frameworks for carbon dioxide separation and capture, ACS Appl. Mater. Interfaces 9 (2017) 4106641077.

[134] Y. Sakata, S. Furukawa, M. Kondo, K. Hirai, N. Horike, Y. Takashima, H. Uehara, N. Louvain, M. Meilikhov, T. Tsuruoka, S. Isoda, W. Kosaka, O. Sakata, S. Kitagawa, Shape-memory nanopores induced in coordination frameworks by crystal downsizing, Science 339 (2013) 193-196.

[135] S. Krause, V. Bon, I. Senkovska, D. M. Többens, D. Wallacher, R. S. Pillai, G. Maurin, S. Kaskel, The effect of crystallite size on pressure amplification in switchable porous solids, Nature Commun. 9 (2018).

[136] M. Kondo, S. Furukawa, K. Hirai, T. Tsuruoka, J. Reboul, H. Uehara, S. Diring, Y. Sakata, O. Sakata, S. Kitagawa, Trapping of a spatial transient state during the framework transformation of a porous coordination polymer, J. Am. Chem. Soc. 136 (2014) 4938-4944.

[137] A. K. Cheetham, T. D. Bennett, F.-X. Coudert, A. L. Goodwin, Defects and disorder in metal organic frameworks, Dalton Trans. 45 (2016) 4113-4126.

[138] D. W. Davies, K. T. Butler, A. J. Jackson, A. Morris, J. M. Frost, J. M. Skelton, A. Walsh, Computational screening of all stoichiometric inorganic materials, Chem 1 (2016) 617-627.

[139] Y. J. Colón, R. Q. Snurr, High-throughput computational screening of metal-organic frameworks, Chem. Soc. Rev. 43 (2014) 5735-5749.

[140] G. Fraux, F.-X. Coudert, Recent advances in the computational chemistry of soft porous crystals, Chem. Commun. 53 (2017) 7211-7221. 